\title{
A Typology of Parental Involvement in Student Experience: A Latent Class Analysis ${ }^{1,2}$
}

\author{
Xiaoliang Zhou \\ Teachers College, Columbia University \\ xz2256@tc.columbia.edu
}

\author{
Alex J. Bowers \\ Teachers College, Columbia University \\ Bowers@tc.edu
}

\begin{abstract}
:
We examine the extent to which there are significantly different types of Parental Involvement in student's high school experience, and what the relationship of these different types may be to long-term student outcomes, such as high school graduation, college going, and specifically for this study, STEM career outcomes. With the dataset the Education Longitudinal Study of 2002 (ELS:2002) which includes 11,727 parents of high school students in the United States, we examine how parents interact with students and schools using Latent Class Analysis (LCA). We identify three significantly different subgroups of parent involvement: Guiding (44.2\%), Lenient (22.3\%), and Advocate (33.5\%). Parental context and demographic factors, such as gender and ethnicity, and school variables, such as private status and school size, are significantly associated with membership across subgroups, which in turn are related to students' education outcomes, such as college enrollment and selection of a STEM career versus other career outcomes.
\end{abstract}

\section{Keywords:}

Parental Involvement, educational outcomes, STEM, hard science, soft science, latent class analysis (LCA), longitudinal study, ELS:2002

\section{INTRODUCTION:}

The purpose of this study is to examine the extent to which there is one or more than one subgroup of parents (a typology) based on parent's interaction with their child's high school education, using data from a nationally generalizable survey of parents linked to their high school student's achievement, education, and career outcomes, the Education Longitudinal Study of 2002 (ELS:2002). Throughout the literature on student academic achievement and overall schooling outcomes, Parental Involvement in their children's schooling has often been a topic of research (Hollingshead, 1949; Hollingshead, 1975; Jeynes, 2007). Parental Involvement has been defined diversely and

\footnotetext{
${ }^{1}$ This document is a preprint of this manuscript published in The High School Journal. Citation: Zhou, X., Bowers, A.J. (2020) A Typology of Parental Involvement in Student Experience: A Latent Class Analysis. The High School Journal, 103(2), p.99-131. https://doi.org/10.1353/hsj.2020.0005

2 This research was supported by a grant from the National Science Foundation (NSF \#1546653). Any opinions, findings, and conclusions or recommendations are those of the authors and do not necessarily reflect the views of funding agencies.
}

inconsistently, as academic aspirations and conveyance of aspirations to children, interaction with children on school issues, interaction with teachers about children, devotion to school activities, or imposing school-related rules at home (Fan $\&$ Chen, 2001). Indeed, the family and home environment are one of the most important areas that influence student achievement (Henderson \& Mapp, 2002; Leithwood, 2009). Yet, parents are often left out of the research on student outcomes, mainly because data from parents are not collected for many datasets, and research on how to help support parent efforts in helping their students and which efforts are most impactful has historically been lacking (Epstein, 1995). This lack of a deep set of research findings is especially alarming in examining student outcomes in Science, Technology, Engineering and Mathematics (STEM), although there have been quite a number of studies, especially those using nationwide data sets (e.g., PISA, the 1980 High School and Beyond Longitudinal Study by the National Opinion Research Center) and meta-analyses, that have examined the relationship between parent involvement in mathematics or science (Anderson et al., 2007; Friedel et al., 2007; Keith et al., 1986; Muller, 1995). However, since STEM schooling is critically involved in a nation's development in the long run, and since family factors such as Parental Involvement in education explain a large amount of the variance in student achievement, it is necessary to explore how a typology of Parental Involvement influences STEM outcomes.

Nevertheless, there is a persistent stream of research and discussion in the media of parent involvement in their student's schooling. For example, the media and some research have begun to investigate a typology of parent involvement, including so-called "helicopter parents" (Kelley, 2008), "tiger parents" (Warner, 2011), "uninvolved parents", or "indulgent parents" (Martin, 2005). Helicopter parents are overinvolved in a child's life (LeMoyne \& Buchanan, 2011). Tiger parents are authoritarian, emphasizing academic achievement over free time and extracurricular activities (Juang, Qin, \& Park, 2013). Uninvolved parents are indifferent, neither supporting nor controlling children, whereas Indulgent parents are permissive, supporting rather than controlling children (Huver et al., 2010).

Although the media has given many anecdotal reports on different types of parents, we are still not sure whether these types of Parent Involvement empirically exist or whether they constitute only a negligible proportion of high school students' parental experiences. Previous literature shows that for high school parental involvement parents typically supervise children's time spent on doing homework and watching TV, 
which has direct or indirect effects on academic achievements (Fehrmann, Keith, \& Reimers, 1987), or participate in school activities, which has no significant effect on graduation (Anguiano, 2004). To clarify these issues, we explored the extent to which there is a typology of Parental Involvement in the high school student experience with indicators drawn from this literature. We also explored the relationship between this typology and covariates and education outcomes. We found that there are three types of Parental Involvement in student experience, including Guiding (44.2\%), Lenient (22.3\%), and Advocate (33.5\%). Based on our findings, Guiding Parental Involvement is defined as having strong interactions and rules at home, yet with low interactions with the school, Advocate Parental Involvement as having strong interactions and rules at home and having strong school ties and interactions, and Lenient Parental Involvement as generally having low responses across the indicators of involvement with low interactions at home and at school. This typology is significantly related to parent variables such as race, SES, and gender, and school variables such as enrollment, and percent Free Lunch. A significant finding is that Parental Involvement is predictive of both education persistence, from high school, to enrolling in college to graduating, and STEM outcomes, such as majoring in STEM majors in college, and entering STEM careers.

\section{LITERATURE REVIEW:}

Since from the 1960's and 1970's (Baumrind, 1967, 1971, 1973) to today, Parental Involvement research is rich and varied and has come to specific conclusions on important outcomes that are related to parental involvement (Domina, 2005; Fan \& Williams, 2010; Jeynes, 2005; Kim, 2009; Kim, An, Kim, \& Kim, 2018). Specifically, Jeynes (2005) performed a meta-analysis on 41 studies from 1974-2000 and categorized the variables that are related to parental involvement as general parental involvement, specific parental involvement, communication, homework, parental expectations, reading, attendance and participation, and parental style. Jeynes (2005) found that general parental involvement is significantly related to academic achievement of urban elementary school children, with effect sizes around 0.7 to 0.75 , which are exceedingly large effect sizes for education research, highlighting the importance of family participation in a child's schooling outcomes. Importantly in Jeynes (2005), the central effects from this prior research on Parental Involvement appeared to be through a creation of an educational atmosphere through expectations (Gregory \& Huang, 2013) and parental style, instead of attending school activities or establishing household rules. Over a decade later, based on six metaanalyses, Jeynes (2018) proposed a Dual Navigation Approach (DNA) model that distinguished and developed school-based components and home-based components in terms of parental involvement and found that cooperation with teachers produced the largest effect size. Jeynes's $(2005,2018)$ meta-analyses are a recent and robust overview of Parental Involvement.

However, while these studies included parent activities and expectations, the meta-analyses did not include information about parents' attitude toward school including the school climate and academic quality. Traditionally, scholars have viewed "parental attitude toward the school" as either a "parental attitude" variable or a broader "parenting" variable but not a "Parental Involvement" variable (Fan \& Chen, 2001; Jeynes, 2005). Yet, while parental attitude is an expression of parental attitudes and parenting, it is also an expression of parental involvement. For example, Wong and Hughes (2006) carried out an exploratory and confirmatory factor analysis and found four parent-reported involvement dimensions among which the first is parental perceptions about school. Also, "parental attitude toward the school" has been considered as a component of Parental Involvement in earlier studies (Medinnus, 1962; Stendler, 1951).

Apart from having influence upon general academic achievement, Parental Involvement has a relationship with STEM outcomes (Science, Technology, Engineering, and Mathematics). To help children who prematurely exclude STEM majors and careers from consideration based on negative impressions of STEM, van Tuijl and van der Molen (2016) overviewed and integrated 95 studies from 1981-2014 on how children make choices and develop a career in the STEM fields, concluding that some parents' negative, stereotyped views on STEM would steer children away from selecting STEM majors or careers, and suggesting that to promote STEM careers, parents use a growth mindset through building competence in children by discussing stereotypical positive notions of the STEM field. Also, Cheng, Kopotic, and Zamarro (2017) found that parent growth mindset tends to lead girls to soft STEM careers but has little influence on if girls enter hard STEM careers. These studies show that students may choose to enter or not to enter general STEM careers or hard / soft STEM careers owing to parents' positive or negative views of STEM. HardSTEM careers are defined as occupations in areas such as"Life and Physical Science, Engineering, Mathematics, and Information Technology Occupations", and soft-STEM careers are defined as occupations in areas such as "Social Science Occupations", "Architecture Occupations", and "Health Occupations" (Cheng, Kopotic, \& Zamarro, 2017). In this "information age" in which we live, more research is needed specifically examining the relationship between Parental Involvement and math and science outcomes.

Despite the diversity of research on Parental Involvement, Fan and Chen (2001) noted that the definition of Parental Involvement is somewhat diffuse and that whether Parental Involvement is related to academic achievement is up to how education outcomes are defined. In their meta-analysis on 25 studies from 1987-1996, Fan and Chen (2001) concluded that the operational definition of Parental Involvement lacks clarity and consistency (Powell-Smith et al., 2000), with Parental Involvement defined as a multitude of behaviors and practices, such as aspirations, communication with children, participation in school functions, communication with teachers, and rules at home. This way of summarizing Parental Involvement is different from Jeynes (2005) that not only mentions practices such as aspirations/expectations, communication, and participation but also considers general parental involvement and 
other aspects of Parental Involvement such as homework, reading, and parental style. Also, Fan and Chen (2001) found that academic achievement is moderately and practically related to Parental Involvement, strongly related to parent's aspirations for their children's education, and weakly related to home supervision. As with Jeynes (2005), the studies analyzed in this meta-analysis lack information related to parents' attitude toward school climate.

The fact that academic achievement is related to Parental Involvement means that a significantly large proportion of the variance in student academic achievement is explainable by the different ways parents involve themselves in student learning processes and experiences. For example, Hoover-Dempsey, Bassler, and Brissie (1987) conducted stepwise multiple regression analyses on a sample of 1,003 teachers and 66 principals in 66 elementary schools in a mid-Southern state, finding that variations in qualities of school settings such as school SES accounted for $52 \%$ of the variance in parent conferences, $27 \%$ of the variance in parent volunteers, $24 \%$ of the variance in parent home tutoring, $22 \%$ of the variance in parent involvement in home instruction programs, and $41 \%$ of the variance in teacher perception of parent support. Thus, the differing characteristics of Parental Involvement are related to contextual factors and school factors.

Once again, we note that it is important and interesting to focus on "high school" students who are at developmental ages. Compared with ethnic minority families, European American families exhibit greater expectations on academics at earlier ages of children and are more likely to influence children's academic achievements in the future (Yamamoto \& Holloway, 2010). Specifically, for Asian American students, meeting parental expectations and internalized motivations mediate between parental pressures and occupation outcomes (Shen, Liao, Abraham, \& Weng, 2014). We acknowledge the developmental timing of the data collection for the ELS:2002 dataset.

\section{Different types of Parental Involvement}

Based on the above literature, we find that almost all of the studies to date have looked at Parental Involvement as a single monolithic group of high to low, yet there are a few studies that have begun to look at types of parents considering that different parents have differing needs, barriers, or ideas (Crozier, 2001; Goodall, 2013). After observing 146 preschool children and their family members in natural settings, Baumrind (1967, 1971, 1973) identified three subtypes of Parental Involvement as authoritative, authoritarian, and permissive based on the differing degrees of parental control over children. Authoritative parents are controlling, demanding, warm, rational, and receptive to communication, with independent, controlled, explorative, and contented children. Authoritarian parents are detached, controlling, and less warm, with unhappy, withdrawn, and distrustful children. Permissive parents are relatively warm, noncontrolling, and nondemanding, with reliant, nonexplorative, and noncontrolled children. In summary, the earlier efforts in theorizing subgroups of Parental Involvement use the criteria of demandingness and attentiveness, or the degree of controlling Zhou \& Bowers (2020) the child and encouraging autonomy, to distinguish subgroups of parents.

Perhaps due to media attention to a perceived and popular stereotype of a tough parenting style of Asian, especially Chinese, parents, some recent studies attempt to discover a typology of Parental Involvement among Chinese parents along the line of demandingness and support. For instance, after doing a longitudinal interview on 72 Chinese immigrant parents and their children in a northeast US city, Qin and Han (2014) found that immigrant Chinese parents in their sample were the opposite of the perception of tiger parents, feeling powerless in dealing with the child's schooling and forcing the child to be prematurely independent. Since parents are themselves struggling to adapt to the new immigrant life, they compel their child to be self-reliant and are thus not demanding on the child. Kim et al. (2013) also found that supportive rather than tiger parents are the most common in Chinese American families. Compared with Baumrind $(1967,1971,1973)$, the recent studies on subgroups of Parental Involvement either aim to have a deep understanding of why parents show specific features of parenting or incorporate new dimensions of parenting, e.g., support, besides demandingness and attentiveness.

For Parental Involvement of Black or Hispanic ethnic groups, there seems to be a focus on demandingness and support also. For instance, using the national data of the 1997 Child Development Supplement to the Panel Study of Income Dynamics, Hofferth (2003) found that African American fathers monitor children more than Hispanic fathers, both showing more responsibility of rearing children than White fathers. On the other hand, with a sample of 481 parents in one district of Texas, Wong and Hughes (2006) found that Black or Hispanic parents are less likely to complete surveys on Parental Involvement than White parents. These findings may be true, but the previous literature may contain potential bias toward minority ethnic groups. The "responsibility" may imply that lack of social capital presses those parents to spend more time on their children's education, and high possibility to not complete questionnaires may indicate that those parents have to work long hours and do not have extra time.

Different from the above studies, some studies define Parental Involvement based on the degree of parents' predominance in interaction with the school. For example, based on previous literature, Goodall and Montgomery (2014) conducted a qualitative study and argued for three types of Parental Involvement as Parental Involvement with the school, Parental Involvement with schooling, and Parental engagement with children's learning. The first subgroup of parents passively receive information from teachers, the second subgroup interchange information with school staff, and the third subgroup have the choice of action or involvement. Parents in the subgroup of Parental engagement with children's learning may have close ties with school by attending school activities and joining parent-school associations. Thus, this study demonstrates the necessity of examining characteristics of how parents interact with school when considering Parental Involvement. 
Collectively, this research on typologies of Parental Involvement (Baumrind, 1967, 1971, 1973; Goodall \& Montgomery, 2014; Kim et al., 2013; Qin \& Han, 2014) foregrounds two common themes. First, these studies highlight the need for two categories of indicators that are associated with how parents are involved in the student experience: student-level indicators and school-level indicators. In typologies involving student-level indicators, demandingness, attentiveness and support appear to be organizing characteristics in designating subgroups of Parental Involvement. In typologies involving school-level indicators, ties and interaction with school seem to be organizing characteristics in designating subgroups of Parental Involvement. Second, the findings from most of the previous studies describe three or four mutually exclusive subgroups of Parental Involvement.

Although the above studies give some descriptions of how parents are involved in student experiences with school, there are still concerns regarding the validity, the generalizability, and sociocultural implications of the findings. First, there is a clear consensus in the literature that Parental Involvement should be measured in a multidimensional fashion (Epstein, 1995; Fan \& Williams, 2010; Grolnick \& Slowiaczek, 1994). However, Parental Involvement research tends to focus on one type of parent, such as the helicopter parents (Hunt, 2008; LeMoyne \& Buchanan, 2011) or tiger parents (Juang, Qin, \& Park, 2013; Kim et al., 2013). Second, most of the aforementioned studies use methods of interviews or observations on a small sample of children and parents from a specific region, so the size and representativeness of the samples raise questions about the generalizability of the findings. Third, for research aimed to explore subgroups of parents, regression or path analyses (Kim et al., 2013) are not the most appropriate. As a central critique in education research with students, teachers, and schools (Bowers, 2010; Bowers \& White, 2014; Bowers, Blitz, Modest, Salisbury, \& Halverson, 2017; Graves \& Bowers, 2018), fitting all parents to a "best fit" regression line ignores the possibility of multiple homogeneous subgroups within the heterogeneous data, as regression analysis fails to capture nuances of the underlying characteristics of how different subgroups of parents interact with their child's education. Also, since the purpose of path analyses is to explore more causal relationships, path analyses cannot address the research purposes of typology studies that aim to explore empirically identified subgroups. Fourth, research suggests that contextual factors, such as school size and enrollment, influence parents' involvement in education (Leithwood \& Jantzi, 2009). Baumrind (1967, 1971, 1973), Goodall and Montgomery (2014), Kim et al. (2013), and Qin and Han (2014) fail to describe the influence of contextual factors on Parental Involvement because the researchers sample children, schools, or families from a small region in the US. Understanding how parent types may differ across contextual factors should be the next frontier for Parental Involvement typology studies. Thus, the motivation of our study is to address these four issues via latent class analysis (LCA), a mixture modeling approach that tests the extent to which there are statistically significant subgroups of homogeneous survey responders from a heterogeneous population across schools in the United States.

Note that parental involvement is strongly dependent on school context and the history of schooling, and therefore lagging parental engagement is not due to group characteristics. For example, private and small high schools tend to require higher frequency of parental participation in school activities (Cusick, 1992). In other words, it is the school features that determine how parents involve themselves in their children's education.

Also note that other parenting typologies in the literature use more extensive parenting measures to identify typologies and these may not be directly comparable to the current study. For example, instead of defining the Advocate subgroup with indicators of volunteering in school and the other variables, previous literature defines Helicopter parenting as behavioral and psychological over-controlling of children (Padilla-Walker \& Nelson, 2012; Schiffrin et al., 2014).

\section{Framework of the Study}

To date little work has been done to understand the extent to which there is a typology of Parent Involvement, and how these potential subgroups are linked to overall student outcomes, especially in STEM. To fill this gap, we explore subgroups of homogeneous parent involvement within a nationally generalizable sample of parents, using latent class analysis (LCA) to determine the extent to which there are statistically significant subgroups of homogeneous Parent Involvement types within the heterogeneous sample (Asparouhov \& Muthén, 2008; Henry \& Muthén, 2010; Jung \& Wickrama, 2008; Samuelsen \& Raczynski, 2013).

Despite the wealth of studies on Parental Involvement and its effects on academic achievement, little is known about the extent to which there are subgroups of parents who are involved (or not) in their child's high school education. For this reason, this study attempts to use an LCA mixture modeling approach to examine a nationally representative dataset, with the aim to explore to what extent there is a typology of Parental Involvement in education, how covariates are correlated with membership in the latent classes, and how the class membership is related to student outcomes. Thus, in this study we ask four research questions:

(1) To what extent is there one or more than one subgroup of Parental Involvement with children's schooling in high school?

(2) To what extent are parent and school covariates, such as family SES and school academic climate, associated with a typology of Parental Involvement?

(3) To what extent are potential Parental Involvement subgroups related to a child's overall schooling outcomes, such as high school and college completion?

(4) To what extent are potential Parental Involvement subgroups related to a child's overall outcomes in STEM in college and careers? 


\section{METHODS:}

\section{Data}

We conducted a secondary analysis on the publically accessible nationally generalizable dataset the Education Longitudinal Study of 2002 (ELS:2002) (Ingels et al., 2007; Ingels et al., 2014). The ELS:2002 is a unique sample of approximately 15,000 students who were in grade 10 in the United States in the 2002 base year. The U.S. National Center for Education Statistics (NCES) collected a range of data on each student including surveys on attitudes, outcomes, and student achievement. NCES then followed up with these students in 2004, 2006, and 2012 (first, second and third follow-ups). In 2002, NCES also conducted a survey with students' parents to investigate parents' involvement in student experiences, such as playing sports with the child and helping with homework.

The ELS:2002 provides us with a unique opportunity to explore subgroups of Parental Involvement in education with a national dataset in four ways. First, ELS:2002 is a nationally representative longitudinal public dataset that includes students' information from grade 10 to four years after graduation from college. Second, the number of parents who responded to the parent survey component of ELS:2002 is large, with $n=11,727$, the final sample size for the LCA analysis here. Third, as the sample is a complex probabilistic sample (Ingels et al., 2007; Ingels et al., 2014), we weighted the outcomes using the statistical weight F1PNLWT, making our conclusions generalizable to the whole population of over three million students who were in grade 10 in the US in 2002. Fourth, ELS:2002 is the most recent comprehensive ten-year longitudinal survey of students and parents in the U.S. at the time of this writing.

\section{Variables}

We drew on the previous literature reviewed above in the Parental Involvement research domain to help guide our selection of variables. We included indicator variables of six dimensions including Parental Involvement at home and in school-related activities (Table 1) such as support, demandingness, attentiveness, school ties, interaction with school, and attitude toward school. Additionally, we controlled for a range of parent demographic variables (Table 2) such as race, gender, marital status, and highest level of education. Also, we examined a range of student outcome variables (Table 3) such as high school graduation, college enrollment, STEM major at college, college graduation, STEM career at age 26, soft STEM career at age 26, and hard STEM career at age 26.

\section{Support}

ELS:2002 included twelve questions each asking parents how often they did a specific activity to support their children. We used questions about advising on courses / programs selection and advising on things troubling 10th-graders (Fan \& Williams, 2010). Survey questions asked parents to rate their frequency of support on a three-point scale. Responses were dichotomized into high to moderate ( $1=$ "often / sometimes") and none $(0=$ "never").

Zhou \& Bowers (2020)

\section{Demandingness}

The ELS:2002 included questions each asking parents how often they showed a demanding behavior to their children. We used questions about rules on TV watching (Amato \& Fowler, 2002; Fan \& Williams, 2010), checking homework (Amato \& Fowler, 2002; Domina, 2005), knowing children's whereabouts (Amato $\&$ Fowler, 2002), and rules about maintaining grade average (Fan \& Williams, 2010). Survey questions asked parents to rate their frequency of demandingness on a four-point scale or existence of demandingness on a two-point scale. Responses were dichotomized into high to moderate ( $1=$ "Always / Usually") and low to none ( $0=$ "Seldom / Never"), or had the original scale of yes $(1=$ "Yes") and no $(0=$ "No" $)$.

\section{Attentiveness}

The ELS:2002 included questions asking parents how often they showed an attentive behavior to their child. We used questions about attending school activities with 10th-grader (Fan \& Williams, 2010), working on homework / school projects with 10th-grader (Amato \& Fowler, 2002), and spending time talking with 10th-grader (Amato \& Fowler, 2002). We also included a question about using a computer to communicate with 10thgrader's school, since research (Graves \& Bowers, 2018) shows that often high school teachers talk about some parents sending them emails several times a day to attend to their child's needs. Survey questions asked parents to rate their frequency of attentiveness on a four-point scale or existence of attentiveness on a three-point scale. Correspondingly, responses were dichotomized into high to moderate $(1=$ "Frequently / Sometimes") and low to none ( $0=$ "Rarely / Never"), or into yes $(1=$ "Yes") and no $(0=$ "No access to a computer in any setting / Don't use a computer for these purposes").

\section{School ties}

The ELS:2002 included questions asking parents how often they attended a school activity. We used questions about belonging to parent-teacher organizations, taking part in parent-teacher organization activities, and acting as a volunteer at the school (Domina, 2005; Fan \& Williams, 2010). Survey questions asked parents to rate the existence of school ties on a two-point scale. Responses had the original scale of yes $(1=$ "Yes") and no $(0=$ "No").

\section{Interaction with school}

The ELS:2002 included questions asking parents how often they interact with the school on some issue. We used questions about fundraising / volunteer work (Domina, 2005) and course selection (Fan \& Williams, 2010). Survey questions asked parents to rate the frequency of interaction on a four-point scale. Responses were dichotomized into frequently $(1=$ "Once or twice / Three or four times / More than four times") and none (0 $=$ "None").

\section{Attitude toward school}

The ELS:2002 included questions asking parents to what extent they agreed with the statement about attitudes towards their child's schooling. We used questions about whether school 
Table 1: Descriptive Statistics of Indicator Variables for Parental Involvement in Education

\begin{tabular}{|c|c|c|c|c|c|}
\hline Variable & Min & Max & Mean & SD & ELS:2002 Variable \\
\hline \multicolumn{6}{|l|}{ Support } \\
\hline $\begin{array}{l}\text { Provide advice about selecting } \\
\text { courses or programs }\end{array}$ & 0 & 1 & 0.90 & 0.294 & BYP56A; $0=$ Never, $1=$ Sometimes $/$ Often \\
\hline $\begin{array}{l}\text { Provide advice about things } \\
\text { troubling 10th-grader }\end{array}$ & 0 & 1 & 0.94 & 0.242 & BYP56F; 0=Never, 1=Sometimes/ Often \\
\hline \multicolumn{6}{|l|}{ Demandingness } \\
\hline $\begin{array}{l}\text { Family rules for } 10 \text { th-grader about } \\
\text { maintaining grade average }\end{array}$ & 0 & 1 & 0.82 & 0.385 & BYP69A; 0=No, 1=Yes \\
\hline $\begin{array}{l}\text { Family rules for } 10 \text { th-grader about } \\
\text { watching TV }\end{array}$ & 0 & 1 & 0.65 & 0.477 & BYP69D; $0=$ No, $1=$ Yes \\
\hline $\begin{array}{l}\text { How often check that homework } \\
\text { completed }\end{array}$ & 0 & 1 & 0.69 & 0.461 & $\begin{array}{l}\text { BYP55A; 0=Never/Seldom, } \\
\text { 1=Usually/Always }\end{array}$ \\
\hline How often know whereabouts & 0 & 1 & 0.99 & 0.120 & $\begin{array}{l}\text { BYP55C; } 0=\text { Never/Seldom, } \\
1=\text { Usually/Always }\end{array}$ \\
\hline \multicolumn{6}{|l|}{ Attentiveness } \\
\hline $\begin{array}{l}\text { Attended school activities with } \\
\text { 10th-grader }\end{array}$ & 0 & 1 & 0.72 & 0.450 & $\begin{array}{l}\text { BYP57A; 0=Never/Rarely, } \\
\text { 1=Sometimes/Frequently }\end{array}$ \\
\hline $\begin{array}{l}\text { Worked on homework/school } \\
\text { projects with 10th-grader }\end{array}$ & 0 & 1 & 0.72 & 0.447 & $\begin{array}{l}\text { BYP57B; } 0=\text { Never/Rarely, } \\
1=\text { Sometimes/Frequently }\end{array}$ \\
\hline $\begin{array}{l}\text { Spent time talking with 10th- } \\
\text { grader }\end{array}$ & 0 & 1 & 0.96 & 0.186 & $\begin{array}{l}\text { BYP57K; 0=Never/Rarely, } \\
\text { 1=Sometimes/Frequently }\end{array}$ \\
\hline $\begin{array}{l}\text { Uses computer to communicate } \\
\text { with 10th-grader's school }\end{array}$ & 0 & 1 & 0.38 & 0.485 & $\begin{array}{l}\text { BYP73; } 0=\text { No access to a computer in any } \\
\text { setting/Don't use a computer for these } \\
\text { purposes, } 1=\text { Yes }\end{array}$ \\
\hline \multicolumn{6}{|l|}{ School ties } \\
\hline $\begin{array}{l}\text { Belong to parent-teacher } \\
\text { organization }\end{array}$ & 0 & 1 & 0.27 & 0.443 & BYP54A; 0=No, 1=Yes \\
\hline $\begin{array}{l}\text { Take part in parent-teach } \\
\text { organization activities }\end{array}$ & 0 & 1 & 0.31 & 0.464 & BYP54C; $0=$ No, $1=$ Yes \\
\hline Act as a volunteer at the school & 0 & 1 & 0.32 & 0.468 & BYP54D; $0=$ No, $1=$ Yes \\
\hline \multicolumn{6}{|l|}{ Interaction with school } \\
\hline $\begin{array}{l}\text { Parent contacted school about } \\
\text { course selection }\end{array}$ & 0 & 1 & 0.27 & 0.443 & $\begin{array}{l}\text { BYP53D; } 0=\text { None, } 1=\text { Once or twice/ Three } \\
\text { or four times/More than four times }\end{array}$ \\
\hline $\begin{array}{l}\text { Parent contacted school about } \\
\text { fundraising/volunteer work }\end{array}$ & 0 & 1 & 0.31 & 0.463 & $\begin{array}{l}\text { BYP53H; } 0=\text { None, } 1=\text { Once or twice/ Three } \\
\text { or four times/More than four times }\end{array}$ \\
\hline \multicolumn{6}{|l|}{ Attitude toward school } \\
\hline $\begin{array}{l}\text { School assigns too little } \\
\text { homework }\end{array}$ & 0 & 1 & 0.22 & 0.414 & $\begin{array}{l}\text { BYP77A; 0= Disagree/ Strongly disagree, } \\
\text { 1=Strongly agree/Agree }\end{array}$ \\
\hline $\begin{array}{l}\text { School preparing students well for } \\
\text { college }\end{array}$ & 0 & 1 & 0.84 & 0.366 & $\begin{array}{l}\text { BYP77E; } 0=\text { Disagree/ Strongly disagree, } \\
\text { 1=Strongly agree/Agree }\end{array}$ \\
\hline $\begin{array}{l}\text { Violence on school grounds is } \\
\text { problem }\end{array}$ & 0 & 1 & 0.17 & 0.374 & $\begin{array}{l}\text { BYP77N; 0= Disagree/ Strongly disagree, } \\
\text { 1=Strongly agree/Agree }\end{array}$ \\
\hline $\begin{array}{l}\text { Lack of discipline in class is } \\
\text { problem }\end{array}$ & 0 & 1 & 0.19 & 0.396 & $\begin{array}{l}\text { BYP77O; } 0=\text { Disagree/ Strongly disagree, } \\
\text { 1=Strongly agree/Agree }\end{array}$ \\
\hline$N$ & 11,72 & & & & \\
\hline
\end{tabular}


assigned too little homework, whether school prepared students well for college, whether violence on school grounds was a problem, and whether lack of discipline in class was a problem (Medinnus, 1962; Stendler, 1951). Survey questions asked parents to rate their degree of attitude on a four-point scale. Responses were dichotomized into positive ( $1=$ "Strongly agree / Agree") and negative ( $0=$ "Disagree / Strongly disagree"). Indicator information for recoding / transformation and descriptive statistics is in Table 1.

Most indicators in our model have proportions of missing data below 5\%. Exceptions are "School assigns too little homework" (7.9\%), "School preparing students well for college" (8.4\%), "Violence on school grounds is problem" (11.2\%), and "Lack of discipline in class is problem" $(11.5 \%)$. We discuss how we handled missingness below.

Note that we dichotomized each indicator following the recommendations from the mixture modeling literature (Collins \& Lanza, 2010). For parsimonious considerations, we ran an LCA because we selected variables for the analysis given the theory and literature discussed throughout the study, and for our dataset, the scales of the different variables are very different across the different domains, from Likert to "never, sometimes, often", to "yes/no". Thus, following the recommendations of the mixture modeling literature, we dichotomized the variables for model identification (Collins \& Lanza, 2010).

\section{Covariates}

Selection of covariates for our model is based on the previous literature that identified parent and school factors that influence characteristics of Parental Involvement in education. The parent factors included in our model are gender (Shek, 1998), ethnicity (Johnson, 2016), socio-economic status (Education Week Research Center, 2017), marital status (Hetherington, 1981; Jackson \& Scheines, 2005), and highest level of education (Aunola, Nurmi, Onatsu-Arvilommi, \& Pulkkinen, 1999; Fleischmann \& de Haas, 2016). The school factors we included are academic climate (Raudenbush, Rowan \& Kang, 1991; Urick \& Bowers, 2014a), private status (Coleman, Hoffer, \& Kilgore, 1982), urbanicity (Raudenbush, Rowan \& Kang, 1991), school size (Leithwood \& Jantzi, 2009; McDowall \& Schaughency, 2017), and \% Free Lunch (Grade 10, SES) (Harwell \& LeBeau, 2010; Okpala, Okpala, \& Smith, 2001). All of the covariates except SES, academic climate, and \% free lunch are dichotomized. Covariate information for recoding/transformation and descriptive statistics is provided in Table 2.

For the covariate of ethnicity, it may not be appropriate to combine all Asian or Hispanic subgroups into a single monolithic category. For instance, the separate subgroups of Asian ethnicity have unique political outlooks and identities, leading to different voting behaviors (Tam, 1995). Likewise, considering all Hispanic subgroups, such as Cubans, Mexicans, and Puerto Ricans, as a monolithic category may ignore withingroup diversity and makes it difficult to care for distinct healthcare needs of specific subgroups (Weinick et al., 2004).
However, the ELS:2002 data do not give specific subgroup identities of Asian or Hispanic ethnicities and so thus we relied on the Asian and Hispanic variables as covariates in the model.

Most covariates in our model have no missing data, or have proportions of missing data below 5\%. Exceptions are academic climate (16.5\%), school size (14.6\%), and percent free lunch (Grade 10, SES) (7.9\%). We note how we handled missing data below.

\section{Distal outcomes}

Previous literature identified student education outcomes associated with Parental Involvement (Ing, 2014; van Tuijl \& van der Molen, 2016). Distal outcomes included in our model are high school dropout, college entrance, college completion, majoring in STEM at college, persisting in STEM career, entering soft STEM careers, and entering hard STEM careers. STEM occupations contain careers in areas of "Life and Physical Science, Engineering, Mathematics, and Information Technology Occupations", "Social Science Occupations", "Architecture Occupations", and "Health Occupations" (Cheng, Kopotic, \& Zamarro, 2017). Whereas typical hard STEM occupations are "Life and Physical Science, Engineering, Mathematics, and Information Technology Occupations", typical soft STEM occupations are "Social Science Occupations", "Architecture Occupations", and "Health Occupations" (Cheng, Kopotic, \& Zamarro, 2017). For the purpose of our research, all the distal outcomes are dichotomized. In Table 3 we provide distal outcome information for the variables for recoding, transformation and descriptive statistics.

Most distal outcomes in our model have low proportions of missing data, such as drop out of high school $(0 \%)$, enrolled in college $(6.8 \%)$, major in STEM at college $(6.8 \%)$, graduate from college (5.5\%). Exceptions are enter STEM career (13.5\%), enter Hard STEM career (13.5\%), and enter Soft STEM career $(13.5 \%)$. Following recommendations for dealing with missing data in national databases (Strayhorn, 2009), for the indicator variables, covariates, and distals, we imputed missing data with the Full Information Maximum Likelihood (FIML) approach (Asparouhov \& Muthén, 2014; Enders, 2010; Vermunt \& Magidson, 2007).

\section{Analytic Model:}

We used a three step Latent Class Analysis (LCA) to investigate the extent to which there is one or more than one subgroup of Parental Involvement (Figure 1). As part of the mixture modeling literature, LCA is a recently emerging analysis technique that has been shown to be well-suited to examining the extent to which there may be statistically significantly different homogenous subgroups within a large heterogeneous sample (Asparouhov \& Muthén, 2008; Collins \& Lanza, 2010; Jung \& Wickrama, 2008; Muthén \& Asparouhov, 2002; Vermunt \& Magidson, 2002), especially in education, with studies for example identifying nationally generalizable typologies of high school dropouts (Bowers, Sprott, \& Taff, 2012), principal leadership (Agasisti, Bowers, \& Soncin, 2019; Urick \& Bowers, 2014b), principal turnover (Boyce \& Bowers, 
Table 2: Descriptive Statistics of Covariates for Parental Involvement in Education

\begin{tabular}{|c|c|c|c|c|c|}
\hline Variable & Min & Max & Mean & SD & ELS:2002 Variable \\
\hline \multicolumn{6}{|l|}{$\begin{array}{l}\text { Parent } \\
\text { variables }\end{array}$} \\
\hline Hispanic & 0 & 1 & 0.11 & 0.314 & $\begin{array}{l}\text { BYPARACE; } 1=\text { Hispanic, no race specified/ } \\
\text { Hispanic, race specified }\end{array}$ \\
\hline $\begin{array}{l}\text { African } \\
\text { American }\end{array}$ & 0 & 1 & 0.11 & 0.317 & $\begin{array}{l}\text { BYPARACE; 1=Black or African-American, non- } \\
\text { Hispanic }\end{array}$ \\
\hline $\begin{array}{l}\text { Asian } \\
\text { American }\end{array}$ & 0 & 1 & 0.07 & 0.258 & $\begin{array}{l}\text { BYPARACE; } 1=\text { Asian, Hawaii/Pac. Islander, non- } \\
\text { Hispanic }\end{array}$ \\
\hline $\begin{array}{l}\text { Highest level } \\
\text { of education }\end{array}$ & 0 & 1 & 0.44 & 0.497 & $\begin{array}{l}\text { BYPARED; } 1=\text { Graduated from college/ Completed } \\
\text { Master's degree or equivalent/ Completed PhD, MD, } \\
\text { other advanced degree }\end{array}$ \\
\hline Female & 0 & 1 & 0.82 & 0.386 & $\begin{array}{l}\text { BYP01; 1=Biological mother/Adoptive } \\
\text { mother/Stepmother/Foster mother/Girlfriend or } \\
\text { partner of parent or guardian/Grandmother/Other } \\
\text { female relative/Other female guardian }\end{array}$ \\
\hline Single & 0 & 1 & 0.20 & 0.398 & $\begin{array}{l}\text { BYP10; 1=Widowed/Separated/Divorced/Never } \\
\text { married }\end{array}$ \\
\hline SES & -1.97 & 1.82 & 0.12 & 0.739 & BYSES1 \\
\hline \multicolumn{6}{|l|}{$\begin{array}{l}\text { School } \\
\text { variables }\end{array}$} \\
\hline $\begin{array}{l}\text { Academic } \\
\text { climate }\end{array}$ & 1.20 & 5.00 & 3.95 & 0.679 & BYA51A-E; $\alpha=0.867$ \\
\hline Private & 0 & 1 & 0.25 & 0.432 & BYSCTRL; 1=Catholic/Other private \\
\hline Urban & 0 & 1 & 0.31 & 0.463 & BYURBAN; 1=Urban \\
\hline Rural & 0 & 1 & 0.21 & 0.406 & BYURBAN; 1=Rural \\
\hline $\begin{array}{l}\text { Small } \\
\text { enrollment }\end{array}$ & 0 & 1 & 0.27 & 0.445 & BYSCENP; $1=1-599$ students \\
\hline $\begin{array}{l}\text { Large } \\
\text { enrollment }\end{array}$ & 0 & 1 & 0.25 & 0.433 & BYSCENP; $1=1200-1999$ students \\
\hline $\begin{array}{l}\text { Extra Large } \\
\text { enrollment }\end{array}$ & 0 & 1 & 0.14 & 0.348 & BYSCENP; $1=2000-2500+$ students \\
\hline $\begin{array}{l}\% \text { Free } \\
\text { Lunch } \\
\text { (Grade 10, } \\
\text { SES) }\end{array}$ & -1.08 & 2.04 & -0.04 & 0.984 & BY10FLP; $z$-score \\
\hline
\end{tabular}

2016), and student reading comprehension levels (BrasseurHock, Hock, Biancarosa, Kieffer, \& Deshler, 2011).

We followed the recommendations of the LCA methods literature (Asparouhov \& Muthén, 2014; Masyn, 2013; NylundGibson \& Masyn, 2016; Zhu, Steele, \& Moustaki, 2017), and analyzed the dataset using a three-step LCA. The first step of the analysis, model enumeration, includes only indicator variables to identify statistically different types of latent classes (a subgroup typology) of Parental Involvement in education. The second step is a multinomial logistic regression of covariates on the probability of inclusion in each of the parent subgroups.

For the third step, we provide two analytic procedures in the LCA step 3 procedure as recommended in Mplus. First, we performed the step 3 ANOVA-like analysis on distal outcomes to examine the extent to which the identified subgroups vary across education outcomes (Vermunt \& Magidson, 2013). Zhou \& Bowers (2020)
Second, we carried out logistic regressions on the distal outcomes where covariates in Step 2 were controlled by being included in the regressions (Vermunt \& Magidson, 2013). This allows us to single out the influence of subgroup membership on distal outcomes so that this influence will not be confounded with influence from parent and school covariates. We provide the overall LCA model in Figure 1. We used Mplus 7.1 (Muthén \& Muthén, 2012) and provide the 3-step LCA Mplus code in the appendix.

\section{RESULTS:}

The purpose of this study is to explore a typology of US high school students' parents with the ELS:2002 dataset, and in this section, we will describe three types of Parental Involvement from the Latent Class Analysis, as well as the covariates that predict membership and the distal outcomes that are significantly correlated with membership, and then distal student outcomes. We then turn to a discussion of the findings. 
Table 3: Descriptive Statistics of Distal Outcomes of Parental Involvement in Education

\begin{tabular}{|c|c|c|c|c|c|c|}
\hline Variable & $N$ & Min & Max & Mean & SD & ELS:2002 Variable \\
\hline Drop out of high school & 11,727 & 0 & 1 & 0.08 & 0.275 & F2EVERDO; 1=Evidence of a dropout episode \\
\hline Enrolled in college & 10,934 & 0 & 1 & 0.44 & 0.496 & F2PS0601; 1= Enrolled in a 4-yr institution \\
\hline $\begin{array}{l}\text { Major in STEM at } \\
\text { college }\end{array}$ & 10,933 & 0 & 1 & 0.20 & 0.401 & $\begin{array}{l}\text { F2MJR2_P; 1=Agriculture or natural resources or related/ Biological and } \\
\text { biomedical sciences/Computer or info sciences or support tech/ Engineering } \\
\text { technologies or technicians/Family or consumer sciences, human } \\
\text { sciences/Health professions or clinical sciences/Mathematics and } \\
\text { statistics/Physical sciences/Social sciences (except psychology) }\end{array}$ \\
\hline Graduate from college & 11,081 & 0 & 1 & 0.41 & 0.491 & $\begin{array}{l}\text { F3TZHIGHDEG; 1=Bachelor's degree or Post-bachelor's certificate/Master's } \\
\text { degree or Post-master's certificate/Doctoral degree }\end{array}$ \\
\hline Enter STEM career & 10,149 & 0 & 1 & 0.15 & 0.357 & $\begin{array}{l}\text { F3STEMOCCCUR; 1=STEM occupation/STEM sub-domain and occupation } \\
\text { type suppressed }\end{array}$ \\
\hline $\begin{array}{l}\text { Enter Hard STEM } \\
\text { career }\end{array}$ & 10,149 & 0 & 1 & 0.07 & 0.249 & $\begin{array}{l}\text { F3STEMOCCCUR; 1= Life and Physical Science, Engineering, Mathematics, } \\
\text { and Information Technology Occupations }\end{array}$ \\
\hline Enter Soft STEM career & 10,149 & 0 & 1 & 0.08 & 0.266 & F3STEMOCCCUR; 1=Social Science Occupations/ Health Occupations \\
\hline
\end{tabular}


Figure 1. Model of the Latent Class Analysis of Parental Involvement in Education

Survey Questions Related to Parental Involvement in Education (Indicators)

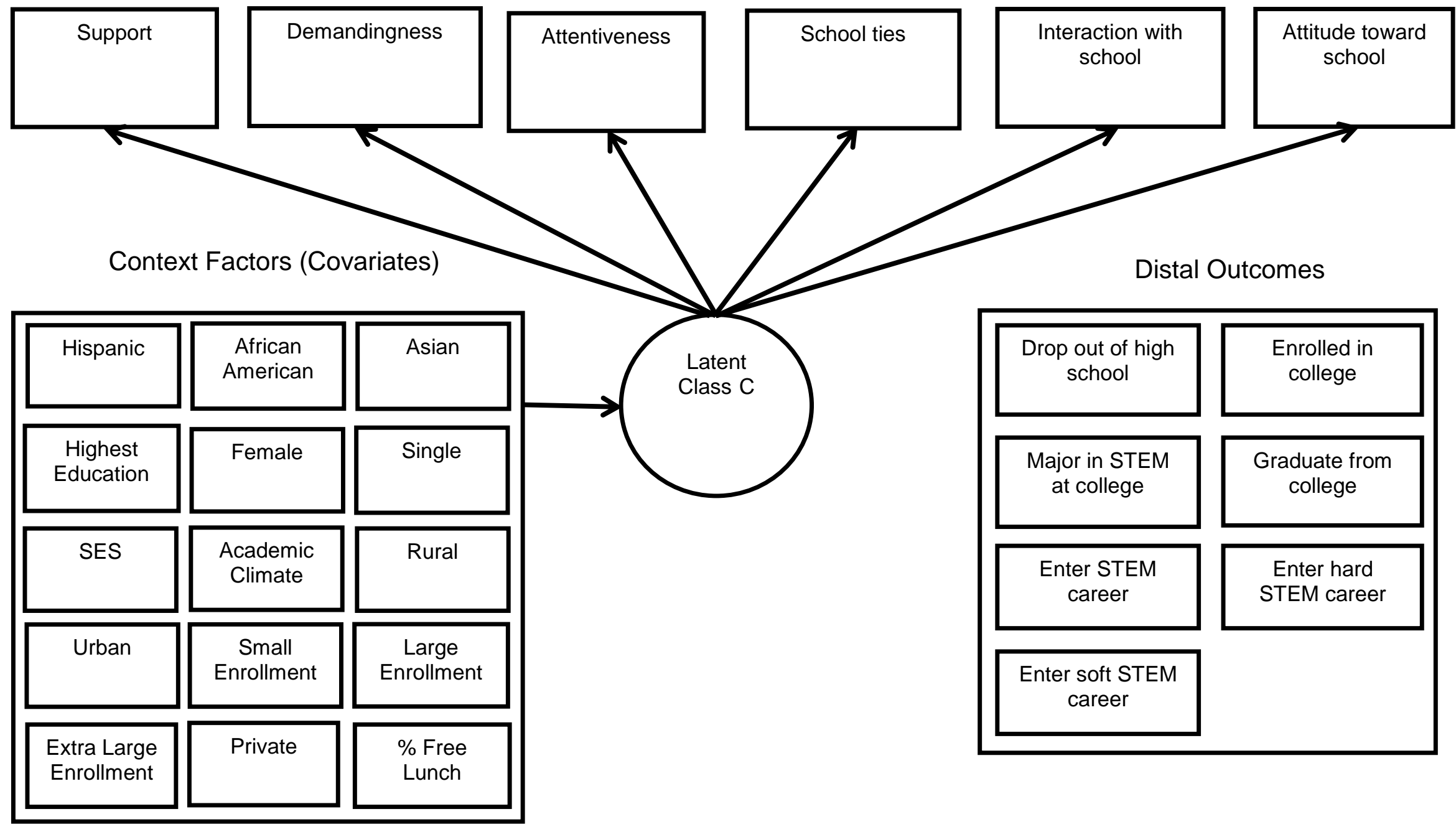

Figure 1: Model of the Latent Class Analysis of Parental Involvement in Education. 
Table 4: Latent Class Analysis Results and Fit Statistics for Parental Involvement in Education

\begin{tabular}{lcccccc}
\hline Model & AIC & BIC & $\begin{array}{c}\text {-Log } \\
\text { Likelihood }\end{array}$ & $\begin{array}{c}\text { LMR Test } \\
\text { for k-1 classes }\end{array}$ & $\begin{array}{c}p \text { - } \\
\text { value }\end{array}$ & Entropy \\
\hline Two Classes & 198527.484 & 198814.900 & 99224.742 & 10736.706 & $<0.001$ & 0.716 \\
Three Classes & $\mathbf{1 9 6 4 4 2 . 7 5 2}$ & $\mathbf{1 9 6 8 7 7 . 5 6 1}$ & $\mathbf{9 8 1 6 2 . 3 7 6}$ & $\mathbf{2 1 1 3 . 4 5 4}$ & $<\mathbf{0 . 0 0 1}$ & $\mathbf{0 . 6 5 8}$ \\
Four Classes & 194832.223 & 195414.425 & 97337.112 & 1641.768 & 0.056 & 0.678 \\
Five Classes & 194045.332 & 194774.927 & 96923.666 & 822.502 & 0.099 & 0.668 \\
Six Classes & 193572.793 & 194449.781 & 96667.397 & 509.818 & 0.490 & 0.640 \\
Seven Classes & 193232.653 & 194257.034 & 96477.327 & 378.122 & 0.763 & 0.628 \\
Eight Classes & 192903.714 & 194075.488 & 96292.857 & 366.981 & 0.345 & 0.618 \\
Nine Classes & 192632.564 & 193951.731 & 96137.282 & 309.499 & 0.218 & 0.618 \\
Ten Classes & 192427.284 & 193893.844 & 96014.642 & 243.978 & 0.763 & 0.632 \\
Eleven Classes & 192247.772 & 193861.725 & 95904.886 & 218.346 & 0.304 & 0.634 \\
Twelve Classes & 192090.374 & 193851.720 & 95806.187 & 196.350 & 0.682 & 0.656 \\
Thirteen Classes & 191941.031 & 193849.770 & 95711.515 & 188.338 & 0.412 & 0.649 \\
Fourteen Classes & 191822.544 & 193878.676 & 95632.272 & 157.646 & 0.787 & 0.636 \\
\hline
\end{tabular}

Note: AIC = Akaike information criteria; BIC=Bayesian information criteria; $\mathrm{LMR}=$ Lo-Mendell-Rubin adjusted likelihood ratio test

Table 5: Average Latent Class Probabilities for Most Likely Latent Class Membership (Row) by Latent Class (Column)

\begin{tabular}{llll}
\hline & Lenient & Advocate & Guiding \\
\hline Lenient & $\mathbf{0 . 8 2 7}$ & 0.020 & 0.153 \\
Advocate & 0.016 & $\mathbf{0 . 8 9 8}$ & 0.085 \\
Guiding & 0.103 & 0.079 & $\mathbf{0 . 8 1 8}$ \\
\hline
\end{tabular}

Following the recommendations for iteratively fitting three-step latent class analysis models, in the first step, the enumeration step, we fit a $k=2$ latent class model, assessed fit, and then fit a $k=3$ class model, and so on, stopping when the model no longer fit the data. We then interpreted the $k-1$ model (Jung \& Wickrama, 2008; Masyn, 2013; Muthén, 2002; Nylund, Asparouhov, \& Muthén, 2007; Samuelsen \& Raczynski, 2013). Table 4 provides the model fit indices and p-values for each iterative model assessed from two latent classes to fourteen latent classes. Based on literature on the LMR test (Lo, Mendell, $\&$ Rubin, 2001), the four-class model had the first nonsignificant fit at $p=0.056$ (Table 4), so the three-class model was the best fit. However, as the model fit research for LCA remains an active area of research (Jung \& Wickrama, 2008; Muthén, 2002; Nylund, Asparouhov, \& Muthén, 2007; Nylund-Gibson \& Masyn, 2016), we also considered the BIC in addition to LMR. The lowest BIC was the thirteen-class model $(\mathrm{BIC}=$ 193849.770). However, to err on the side of a more parsimonious and conservative model fit and avoid model overinterpretation as well as to avoid issues with power (Dziak, Lanza, \& Tan, 2014), we argue for the three-class model as the LMR statistic is more conservative than BIC (Tofighi \& Enders, 2008).
The three-class model fit the data well with AIC $=196442.752$, BIC $=196877.561,-$ Log Likelihood=98162.376, LMR=2113.454 $(p<0.001)$, and entropy $=0.658$. Table 5 shows average latent class probabilities for most likely latent class membership by latent class, with the proportions representing the probability of an individual being classified into a particular latent class subgroup group for the model. Examining numbers on the diagonal, the model fit the data well for all three groups with high probabilities all over 0.8 , and relatively low probabilities on the off-diagonal.

From this analysis, we identified that there are at least three statistically significant different groups of Parental Involvement and named the subgroups Guiding (44.2\%), Lenient (22.3\%), and Advocate (33.5\%) based on the significant differences across the indicator variables. Figure 2 is an indicator plot illustrating the proportions of the indicators for each subgroup.

First, for largest responding subgroup, the Guiding subgroup, the LCA model identified an interesting group of Parental Involvement in which parents have high responses across all indicator questions except for direct involvement in their child's high school. The Guiding subgroup (Figure 2, dashed gray line) 
Figure 2 Indicator Plots of Latent Class Analysis Results

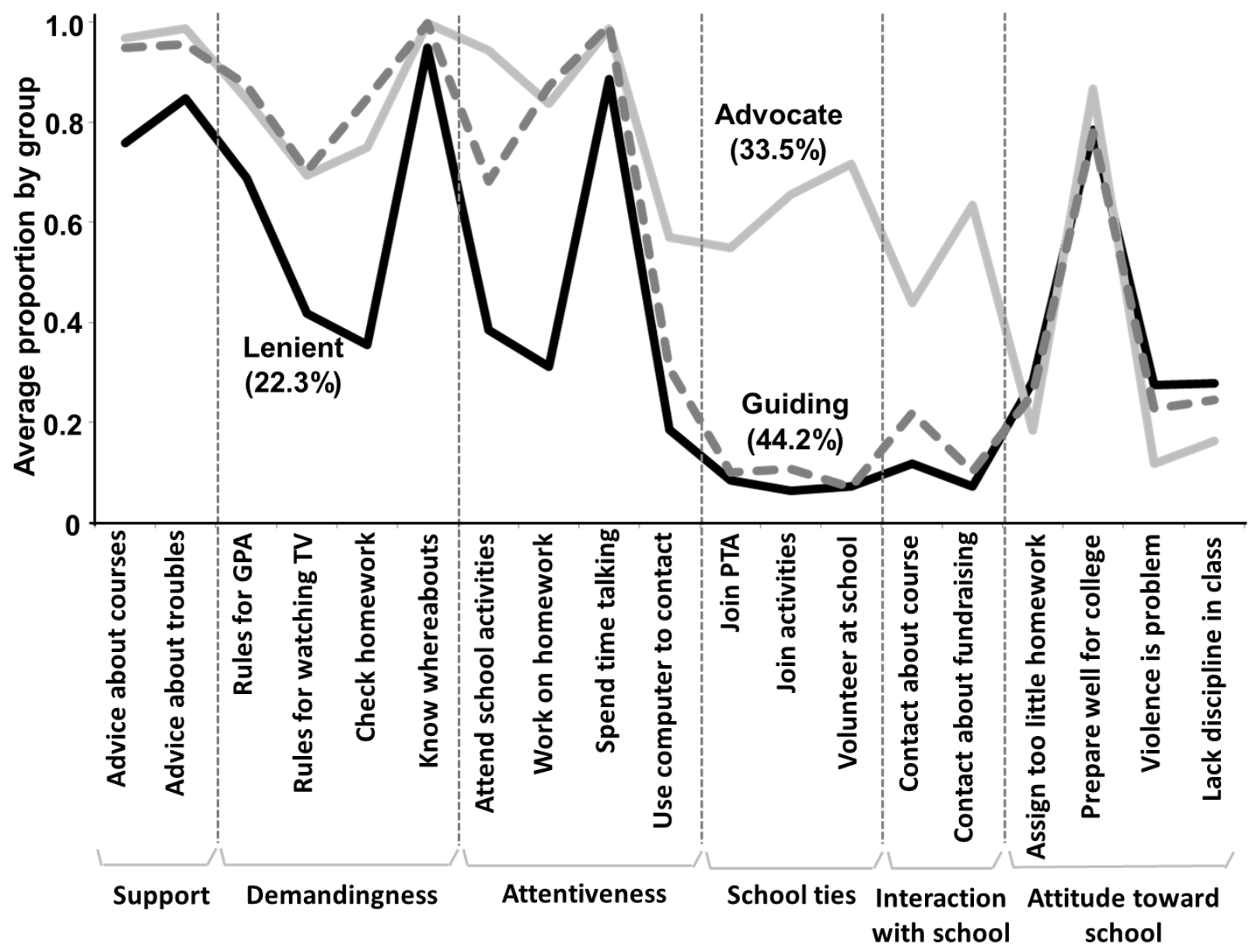

Figure 2: Indicator Plots of Latent Class Analysis Results. Parents' response patterns to the 19 dichotomously scaled ELS: 2002 parent survey items. The $x$-axis displays all the items grouped by the similarity. The $y$-axis presents the proportion of each subgroup with responses such as "yes" or "agree". One possible typology for these three subgroups is Guiding (44.2\%), Lenient (22.3\%), and Advocate (33.5\%).

represents $44.2 \%$ of the sample, the largest subgroup. This subgroup of parents features activeness in facilitating learning in home environments through activities like advising on course / program selection $(95.0 \%)$, making rules on watching TV (70.4\%), and working on homework / projects $(87.2 \%)$ with their student. However, Guiding parents are not enthusiastic in having contacts with school. For example, these parents have low responses for joining parent-teacher associations (10.1\%), or participating in fundraising / volunteering work (10.2\%). The Guiding parent subgroup also have low responses to contacting the school about courses. Generally, Guiding parents have a positive attitude toward school.

The LCA model also identified an active subgroup of Parental Involvement, with parents having high responses across almost all indicators. The Advocate group consists of $33.5 \%$ of the sample (Figure 2, solid gray line), with the highest proportions of positive responses in most indicators. The Advocate parents are typified by both high involvement in facilitating student learning in the home environment, in a similar pattern to the Guiding parent subgroup, but the Advocate subgroup also has high involvement in parent-teacher organization activities $(65.6 \%)$ and contacting school about fundraising / volunteering $(63.6 \%)$ and student course selection (44.0\%). Additionally, Advocate parents have the highest attendance at school activities $(65.6 \%)$ of all three subgroups, and the lowest responses to violence (11.7\%) and lack of discipline (16.2\%) as issues in the school.

In direct contrast to Advocate parents, the Lenient parents (Figure 2, solid black line) are the least active across all indicator variables, with the smallest proportion of $22.3 \%$ in the sample. The Lenient subgroup has the lowest proportion of requirements for students maintaining their high school GPA (68.9\%) or limiting time for watching TV (41.9\%). Lenient parents have the lowest responses out of the four subgroups in 
giving advice to their child on selecting courses or programs $(75.9 \%)$ or on troubling issues $(84.9 \%)$. Lenient parents also have the lowest proportion in terms of being attentive to children's needs, such as homework / projects $(31.2 \%)$ and talking with 10th-graders (88.7\%). The Lenient subgroup also have low responses on connections with schools, with the lowest percentage for taking part in parent-teacher activities $(6.3 \%)$ or contacting schools about fundraising / volunteering (7.2\%). However, the Lenient parent subgroup has the highest response to violence is a problem in the school $(27.5 \%)$ and that there is a lack of discipline in the school (27.8\%). Across all three subgroups, there was little variance in parent responses to the amount of homework assigned by the school or how well the school prepares students for college.

We also examined how the covariates are associated with the probability of a parent belonging to one of the three subgroups (Table 6), with the Guiding group as the reference group. Given that odds ratios less than 1.0 are difficult to interpret, here for odds ratios below 1.0, we invert the odds ratio. For parent covariates, results show that Hispanic parents are 1.82 times less likely to be Advocate than Guiding parent subgroup (1/0.55) ( $p$ $=0.001)$, and African American parents 1.79 times less likely to be to be Lenient than the Guiding parent subgroup (1/0.56) $(p=$ 0.001 ). Asian parents are 1.65 times more likely to be Lenient than Guiding ( $p=0.015)$, and 1.92 times less likely to be Advocate than the Guiding parent subgroup (1/0.52) ( $p=0.005)$. Parents with Bachelor or higher degrees are 1.35 times more likely to be Lenient than the Guiding parent subgroup ( $p=$ 0.038 ). Female parents are 1.61 times less likely to be Lenient than the Guiding parent subgroup $(1 / 0.62)(p<0.001)$. Single parents are 1.75 times less likely to be Advocate than the Guiding parent subgroup $(1 / 0.57)(p<0.001)$. Parents with SES one standard deviation higher than the average are 2.25 times more likely to be Advocate than the Guiding parent subgroup ( $p$ $<0.001$ ), and 1.72 times less likely to be Lenient than the Guiding parent subgroup $(1 / 0.58)(p<0.001)$.

For school covariates, for the school that the parent's student attended, results show that for students who attend a private school, parents are 1.62 times more likely to be Lenient than the Guiding parent subgroup $(p=0.018)$ and are 2.79 times more likely to be Advocate than the Guiding parent subgroup ( $p<$ 0.001). Similarly, when their child attends a small school (less than 599 students), parents are 1.63 times more likely to be Advocate than the Guiding parent subgroup $(p<0.001)$. By contrast, when their child attends a large school $(1,200-1,999$ students students), parents are 1.25 times less likely to be Advocate than the Guiding parent subgroup (1/0.80) ( $p=0.042)$. When their child attends a school where the percentage of students eligible for free and reduced lunch is one standard deviation higher than the average, parents are 1.16 times less likely to be Advocate than the Guiding parent subgroup (1/0.86) $(p=0.008)$. In sum, for the covariates, the Guiding parent subgroup are more often Hispanic and African American, female, a single parent family, and lower SES with their students in large enrollment schools with higher percentages of free and reduced price lunch students. The Lenient parent subgroup is Zhou \& Bowers (2020) more likely to be Asian American, have the highest level of education, and to send their students more often to private school than Guiding subgroup parents. Advocate parents are more likely to be higher SES with the highest likelihood of having students enrolled in private schools as well as students in small enrollment schools.

Finally, we present the relationship between Parental Involvement typology membership and student distal outcomes in Table 7 and Table 8 . Table 7 indicates pair-wise comparison chi-square-tests results where almost all pairs of classes differ significantly on each of the seven distal outcomes. However, when controlling for the covariates in running the logistic regressions on distal outcomes, results are somewhat different. Table 8 shows comparisons of subgroups of Parental Involvement on distal outcomes, with the Guiding subgroup as reference. Children of parents in the Advocate subgroup have a mean dropout rate of 0.05 , significantly lower than children of the Guiding Parental Involvement subgroup $(M=0.12, p<$ 0.001), and children of Lenient Parental Involvement subgroup parents have a mean dropout rate of 0.16 , significantly higher than children of Guiding Parental Involvement subgroup $(p=$ 0.011), controlling for the covariates in the model. Children of the Advocate Parental Involvement subgroup have mean college enrollment rates of 0.55 , significantly higher than children of the Guiding Parental Involvement typology subgroup $(M=0.30, p<$ 0.001). Children of Advocate parents have a mean rate of majoring in STEM in college of 0.23, significantly higher than children of the Guiding Parental Involvement subgroup $(M=$ $0.15, p=0.002$ ). Children of Advocate parents have a mean college graduation rate of 0.50 , significantly higher than children of the Guiding Parental Involvement subgroup $(M=0.28, p<$ 0.001 ), and children of the Lenient Parental Involvement typology subgroup have a mean college graduation rate of 0.31 , significantly higher than children of Guiding Parental Involvement $(p<0.001)$. Children of the Advocate Parental Involvement subgroup have mean rates of entering STEM careers by the third follow-up of ELS:2002 in 2012 when the majority of the students were age 26 of 0.17 , significantly higher than children of Guiding Parental Involvement typology subgroup $(M=0.12, p=0.048)$. Entering a hard STEM occupation at age 26 (a the time of the third follow-up to ELS:2002 in 2012) is not significantly related to the Parent Involvement typology, controlling for the covariates. Children of Advocate Parental Involvement have a mean of entering soft STEM careers of 0.08 , significantly higher than children of Guiding Parental Involvement $(M=0.06, p=0.027)$.

In sum, when controlling for the covariates on the distal outcomes, for dropping out of high school, students from the Lenient Parental Involvement typology subgroup drop out the most, followed by Guiding, with the lowest dropout rates of the Advocate subgroup. For enrolling in college, while there is little difference in enrollment rates between Guiding and Lenient subgroups, students from the Advocate parent subgroup enroll at much higher rates. For majoring in STEM in college, students from the Guiding Parent Involvement subgroup enroll at the lowest rates, with Lenient in the middle, and Advocate with the 
Table 6: Means and Odds Ratios for Covariates Using Guiding Parental Involvement as the Reference Group

\begin{tabular}{|c|c|c|c|c|c|c|c|c|}
\hline \multirow[t]{2}{*}{ Variables } & \multicolumn{2}{|c|}{$\begin{array}{c}\text { Guiding } \\
(44.2 \%) \\
\text { High-low }\end{array}$} & \multicolumn{3}{|c|}{$\begin{array}{l}\text { Lenient } \\
(22.3 \%) \\
\text { Low-low }\end{array}$} & \multicolumn{3}{|c|}{$\begin{array}{c}\text { Advocate } \\
(33.5 \%) \\
\text { High-high }\end{array}$} \\
\hline & Mean & $\begin{array}{l}\text { Odds } \\
\text { Ratio }\end{array}$ & Mean & $\begin{array}{l}\text { Odds } \\
\text { Ratio }\end{array}$ & $p$-value & Mean & $\begin{array}{l}\text { Odds } \\
\text { Ratio }\end{array}$ & $p$-value \\
\hline \multicolumn{9}{|l|}{ Parent variables } \\
\hline Hispanic & 0.14 & -- & 0.16 & & 0.091 & 0.06 & $0.55^{* *}$ & 0.001 \\
\hline $\begin{array}{l}\text { African } \\
\text { American }\end{array}$ & 0.13 & -- & 0.10 & $0.56^{* *}$ & 0.001 & 0.10 & & 0.153 \\
\hline $\begin{array}{l}\text { Asian } \\
\text { American }\end{array}$ & 0.03 & -- & 0.05 & $1.65^{*}$ & 0.015 & 0.02 & $0.52^{* *}$ & 0.005 \\
\hline $\begin{array}{l}\text { Highest level } \\
\text { of education }\end{array}$ & 0.33 & -- & 0.30 & $1.35^{*}$ & 0.038 & 0.55 & & 0.062 \\
\hline Female & 0.84 & -- & 0.79 & $0.62^{* * * *}$ & $<0.001$ & 0.84 & & 0.733 \\
\hline Single & 0.24 & -- & 0.27 & & 0.207 & 0.14 & $0.57^{* * * *}$ & $<0.001$ \\
\hline SES & -0.06 & -- & -0.18 & $0.58^{* * * *}$ & $<0.001$ & 0.36 & $2.25^{* * *}$ & $<0.001$ \\
\hline \multicolumn{9}{|l|}{ School variables } \\
\hline $\begin{array}{l}\text { Academic } \\
\text { climate }\end{array}$ & 3.81 & -- & 3.80 & & 0.809 & 4.00 & & 0.141 \\
\hline Private & 0.04 & -- & 0.05 & $1.62^{*}$ & 0.018 & 0.16 & $2.79^{* * * *}$ & $<0.001$ \\
\hline Urban & 0.24 & -- & 0.27 & & 0.266 & 0.26 & & 0.279 \\
\hline Rural & 0.24 & -- & 0.22 & & 0.142 & 0.23 & & 0.788 \\
\hline $\begin{array}{l}\text { Small } \\
\text { enrollment }\end{array}$ & 0.17 & -- & 0.17 & & 0.571 & 0.24 & $1.63^{* * *}$ & $<0.001$ \\
\hline $\begin{array}{l}\text { Large } \\
\text { enrollment }\end{array}$ & 0.32 & -- & 0.30 & & 0.600 & 0.28 & $0.80^{*}$ & 0.042 \\
\hline $\begin{array}{l}\text { Extra Large } \\
\text { enrollment }\end{array}$ & 0.20 & -- & 0.23 & & 0.254 & 0.16 & & 0.340 \\
\hline $\begin{array}{l}\% \text { Free Lunch } \\
\text { (Grade 10, } \\
\text { SES) }\end{array}$ & 0.21 & -- & 0.21 & & 0.290 & -0.14 & $0.86^{* *}$ & 0.008 \\
\hline
\end{tabular}

Note: $* p<0.05 ; * * p<0.01 ; * * * p<0.001$

Table 7: Means and Pair-wise Comparison Chi-square Test Results for Distal Student Outcomes

\begin{tabular}{lccccccc}
\hline & $\begin{array}{c}\text { Guiding } \\
(44.2 \%) \\
\text { High-low } \\
(1)\end{array}$ & $\begin{array}{c}\text { Lenient } \\
(22.3 \%) \\
\text { Low-low } \\
(2)\end{array}$ & $\begin{array}{c}\text { Advocate } \\
(33.5 \%) \\
\text { High-high } \\
(3)\end{array}$ & & $\begin{array}{c}p \text { - } \\
\text { value }\end{array}$ & $p$-value & $p$-value \\
\cline { 2 - 5 } & Mean & Mean & Mean & 1 vs. 2 & 1 vs. 3 & 2 vs. 3 \\
Distal Outcomes & 0.12 & 0.16 & 0.05 & $\mathbf{0 . 0 1 1}$ & $<\mathbf{0 . 0 0 1}$ & $<\mathbf{0 . 0 0 1}$ \\
Drop out of high school & 0.30 & 0.31 & 0.55 & $\mathbf{0 . 0 0 1}$ & $<\mathbf{0 . 0 0 1}$ & $<\mathbf{0 . 0 0 1}$ \\
Enrolled in college & 0.15 & 0.15 & 0.23 & $\mathbf{0 . 0 2 6}$ & $<\mathbf{0 . 0 0 1}$ & $<\mathbf{0 . 0 0 1}$ \\
Major in STEM at college & 0.28 & 0.31 & 0.50 & $<\mathbf{0 . 0 0 1}$ & $<\mathbf{0 . 0 0 1}$ & $<\mathbf{0 . 0 0 1}$ \\
Graduate from college & 0.12 & 0.13 & 0.17 & $\mathbf{0 . 0 2 7}$ & $<\mathbf{0 . 0 0 1}$ & $\mathbf{0 . 0 0 2}$ \\
Enter STEM career & 0.06 & 0.06 & 0.07 & 0.115 & $<\mathbf{0 . 0 0 1}$ & 0.154 \\
Enter hard STEM career & 0.06 & 0.06 & 0.08 & 0.156 & $<\mathbf{0 . 0 0 1}$ & $\mathbf{0 . 0 0 8}$ \\
Enter soft STEM career & & & & & & & \\
\hline
\end{tabular}


Table 8: Logistic Regressions (Step-2 Covariates Controlled) on Distal Student Outcomes Using Guiding Parental Involvement as the Reference Group

\begin{tabular}{|c|c|c|c|c|c|}
\hline Variables & $\begin{array}{c}\text { Guiding } \\
(44.2 \%) \\
\text { High-low } \\
\text { Mean }\end{array}$ & $\begin{array}{c}\text { Lenient } \\
(22.3 \%) \\
\text { Low-low } \\
\text { Mean }\end{array}$ & $p$-value & $\begin{array}{c}\text { Advocate } \\
(33.5 \%) \\
\text { High-high } \\
\text { Mean }\end{array}$ & $p$-value \\
\hline Drop out of high school & 0.12 & 0.16 & 0.011 & 0.05 & $<0.001$ \\
\hline Enrolled in college & 0.30 & 0.31 & 0.073 & 0.55 & $<0.001$ \\
\hline Major in STEM at college & 0.15 & 0.15 & 0.536 & 0.23 & 0.002 \\
\hline Graduate from college & 0.28 & 0.31 & $<0.001$ & 0.50 & $<0.001$ \\
\hline Enter STEM career & 0.12 & 0.13 & 0.377 & 0.17 & 0.048 \\
\hline Enter hard STEM career & 0.06 & 0.06 & 0.110 & 0.07 & 0.754 \\
\hline Enter soft STEM career & 0.06 & 0.06 & 0.514 & 0.08 & $\mathbf{0 . 0 2 7}$ \\
\hline
\end{tabular}

highest college enrollment. For student STEM career occupations at age 26 , while there is little difference in the rates for students from Guiding and Lenient Parent Involvement typology subgroups, students from the Advocate subgroup are much more likely to go into a STEM occupation overall, and a soft STEM occupation specifically.

\section{DISCUSSION:}

This study enriches current literature on Parental Involvement in education by using multidimensional measures of Parental Involvement, with a publicly available national generalizable dataset. This study explores the types of Parental Involvement in education, what factors predict membership in those groups, and how this typology is related to student STEM outcomes. The results of the study provide statistically significant evidence that each type of Parental Involvement is predictive of significantly different student outcomes, including high school dropout, college entrance, college graduation, STEM majoring, STEM career selection, and soft STEM career selection. Since math and science are especially important for the development of a nation in the "information age", we need more research on how Parental Involvement is related to math and science outcomes. For the first time, this study empirically identifies three types of Parental Involvement in education using a large nationally generalizable U.S. sample.

Overall for the three groups of the Parental Involvement typology, for the largest subgroup (44.2\%) the Guiding subgroup have strong interactions and rules at home, yet have low interactions with the school. These parents are much more often Hispanic and African American, single parent families, lower SES than Advocate yet higher SES than Lenient, the least likely to have students in private schools, and in comparison to Advocate, are more likely to have students in large enrollment schools with higher percentages of free and reduced price lunch students. Students of the Guiding parent subgroup have the second highest high school dropout rate, and the lowest graduation rate from college, yet are similar in all other distal outcomes with the Lenient subgroup. The Advocate subgroup, as the second largest $(33.5 \%)$, have strong interactions and rules at home and have the strongest school ties and interactions. The Advocate parent subgroup are the highest SES with the highest rates of students in private schools, with small enrollment. Students from Advocate subgroup families have the highest rates of positive distal outcomes, including the lowest high school dropout rate, and highest rates of enrollment in college, graduation from college, and STEM careers. However, there is no difference between all three groups on the rates that students enter hard STEM occupations by age 26. The Lenient is the smallest subgroup $(22.3 \%)$ and are typified as generally having the lowest responses across the indicators with the lowest interactions at home and at school. However, this group has the highest responses to violence and discipline as issues at their student's school. Lenient subgroup parents are more likely to be Asian American and the highest level of education, while also having the lowest SES and the second highest rate of students attending private schools. Students from the Lenient parent subgroup have the highest rate of high school dropout but also the second highest rate of college graduation, while being similar on other student distal outcomes to the Guiding subgroup.

In considering these outcomes, acknowledging that our results are not causal and are only correlational in nature, our results indicate that students from the Advocate Parent Involvement typology subgroup appear to have higher overall schooling outcomes by age 26 , controlling for the covariates in the model, while students from the Guiding and Lenient subgroups have somewhat similar outcomes, but with students from the Lenient Parent Involvement subgroup having both the highest rates of dropout as well the second highest rates of college graduation. From Figure 2 on the indicator plot, for the theory of Parental Involvement, our results suggest that what appears to separate the Advocate parent subgroup is their interaction with the school across a wide variety of issues, from attending school activities, to volunteering at the school, and contacting the school. Given that many of the distal outcomes are statistically indistinguishable when controlling for the covariates for the Guiding and Lenient subgroups, it appears that at the least, home support, demandingness, and attentiveness are perhaps necessary but insufficient. However, we acknowledge that the Lenient 
group is most likely made up of additional unidentified nested subgroups, as there appears to be a variety of conflicting variables associated with this group, including highest education but lowest SES, and highest high school dropout rate, but second highest college graduation rate. We encourage additional research in this area. Nevertheless, the point that the Advocate Parent Involvement subgroup is typified by their interaction with the school and that these students have the strongest positive distal outcomes at age 26, is a central finding of this study.

The Parental Involvement typology in the present study has both similarities to and differences from typologies of previous studies (Baumrind, 1967, 1971, 1973; Goodall \& Montgomery, 2014; LeMoyne \& Buchanan, 2011). First, in terms of showing demandingness and support to the child at home, both the Guiding parents (44.2\%) and Advocate parents (33.5\%), who actively interact with their child, have family rules, and attend to child's academic and living needs, are similar to Baumrind's (1967, 1971, 1973) authoritative parents who are controlling, demanding, warm, rational, and receptive to communication. Second, in terms of showing demandingness and support to the child outside school, the Lenient parents (22.3\%), having the lowest proportion of parents who say that they focus on student support, demandingness in academic achievement, or attend to children's needs, are similar to Baumrind's $(1967,1971,1973)$ permissive parents who are relatively warm, noncontrolling, and nondemanding. Third, in terms of maintaining close ties with the school, the Advocate parents are similar to Goodall and Montgomery's (2014) parents in the subgroup of Parental engagement with children's learning who have the choice of action or involvement. The Advocate parents are enthusiastic in having close ties and contacts with the school, joining parentteacher organizations and participating in school activities. We posit that it is the Advocate subgroup that most closely aligns with past media conceptions of the "helicopter" parent, as these parents are typified by their high frequency of interaction with the school (LeMoyne \& Buchanan, 2011). On the contrary, the Guiding parents and the Lenient parents are similar to Goodall and Montgomery's (2014) parents in the subgroup of Parental Involvement with the school who passively receive information from teachers. Fourth, different from previous studies (Baumrind, 1967, 1971, 1973; Goodall \& Montgomery, 2014; LeMoyne \& Buchanan, 2011), the three subgroups of parents in our findings all have extra features of general satisfaction with the school.

Our findings that Parental Involvement is related to contextual differences speak to previous literature. First, our finding of the Lenient and the Guiding Parental Involvement subgroups where parents have very low proportions of contacts with schools reinforces previous literature that parents with little contact with the school tend to be "low-income, linguistically, ethnically, or culturally diverse" (Lightfoot, 2004, p.99). Interestingly, our findings are incongruent with the popular impression that Asian American parents, the so-called tiger parents, tend to have strict family rules and high academic expectation of their children. Rather, Asian American parents are most likely to be in the Lenient subgroup (Table 6), a result consistent with research Zhou \& Bowers (2020) results that, while struggling with pressure of adapting to new immigrant life, immigrant Chinese parents leave their children to be self-dependent (Qin \& Han, 2014). Our findings also agree with Kim et al. (2013) who find American Chinese parents most likely to be supportive. However, since our data were based on self-reported surveys, it is possible that Asian parents tended to have high expectations on the child and said they were lenient even if they were harsh. Second, we find that Lenient parents are more likely to have at least a four-year college degree. We hypothesize that this is because higher education makes people cherish freedom or because higher degrees mean high-pressure jobs without extra time for childrearing. This hypothesis needs further research. Third, Advocate parents are much less likely to be single parents. This makes sense as perhaps two parents have more time and capacity to be involved in the school. Fourth, Advocate parents are more likely to have high SES or send the child to private or small schools or schools with low percentage Free Lunch (Grade 10, SES), whereas Lenient parents are more likely to be low SES. Perhaps, families of higher SES have more time to participate in school activities (Goldring \& Phillips, 2008) and lower SES parents may have work or location constraints (Smrekar \& Cohen-Vogel, 2001). However, returning to the non-causal conclusions of this study, private or small schools also are known to provide greater opportunities and require more participation of parents (Cusick, 1992), and so having a student in a private or small school could potentially cause a parent to be in the Advocate subgroup because of these requirements, rather than the other way around.

This issue is related to social justice. Although the Advocate Parental Involvement is related to more optimal schooling outcomes, it is possible that this has less to do with the approach that parents select and more about the social capital of these parents that allows them to be more closely integrated in the power and political structure of the school (Cusick, 1992). As we found, Advocate parenting is more likely to occur in smaller, private, higher SES schools and these parents are less likely to be lower income and minority. So, instead of blaming the parents, it is the power structures, or structural and political dynamics, that shape parents' involvement in school. Factors such as "the system", inequities across schools, poverty, and historical disadvantage all bear responsibility for inequalities, parental engagement, and school expectations.

By describing these findings, schools can engage rich and poor families who might have different capacities based on social advantages. These findings can especially help historicallydisadvantaged people since schools can address social justice issues by working to understand family interactions with school through family context. These findings can help schools understand how different types of parental involvement are associated with different SES and school structures, in which schools serve the needs of families.

In considering the findings on student STEM occupation outcomes by the third 2012 follow-up of ELS:2002 when students are most likely at age 26 , our findings provide a novel contribution to the Parental Involvement literature as well as to 
the evolving literature on parent involvement in promoting STEM outcomes. While we find no difference in STEM occupation outcomes of students from Guiding and Lenient parent subgroups, we find moderate evidence that students from Advocate Parent Involvement subgroup families enter STEM careers at higher rates as well as enter soft STEM careers at higher rates. As the Advocate subgroup interacts with schools the most, this finding is incongruent with previous findings that interaction with the school, like attending school events and volunteering, has little influence on education outcomes (Henderson \& Mapp, 2002). However, in comparison to the results from Jeynes' (2005) meta-analysis of Parental Involvement, our results agree in that the role of household rules may not have a strong relationship with overall student academic outcomes. Also, our results speak to findings of Cheng, Kopotic, and Zamarro (2017) that positive parental involvement may help promote students entering soft STEM careers.

This study is not a causal analysis. The students with stronger college outcomes had parents who participated more in the schools. One misinterpretation is that just by participating more in the life of the school, a parent's child's outcomes will improve. This is not our claim. Rather, there most likely is a complex interrelationship between how parents are involved in a child's schooling and education outcomes. The survey items are quite coarse on this issue, and so we rely on the previous qualitative literature (Cusick, 1992) that notes that higher SES parents tend to be able to gain resources at school favorable for their children.

\section{LIMITATIONS:}

Although we believe that the findings of the present study are robust, we recognize that our study is limited in eight key ways. First, the ELS:2002/12 data were initially collected in the base year more than a decade prior to the present study. Given that Parental Involvement is an active research domain, the data collected in one given year might not fully represent how parents are involved in education at any time before or after 2002/12. However, since our goal is to explore how a Parental Involvement typology of parents with students in high school influences long-term student academic outcomes, we encourage future research to continue to examine large longitudinal nationally generalizable datasets similar to ELS:2002, such as the multiple other longitudinal datasets from NCES both more recent and older. Second, the results of the LCA model produced a strong model fit of at least three significantly different groups of Parental Involvement. However, in considering the BIC identified in the literature that determines the best model fit (Jung \& Wickrama, 2008; Muthén, 2002), there could be up to 13 different subgroups that can be identified in the data. Still, we decided on the parsimonious three-class model, using the conservative estimation of the LMR test to avoid overinterpretation of the model. Additionally, a well-known issue with mixture models like LCA is unidentified nested subgroups (Bauer \& Curran, 2003). In the present study we worked to avoid over-extraction of the latent classes, and thus may have multiple unidentified nested subgroups. At the minimum, a somewhat different model, perhaps excluding the four "attitude toward school" indicators that are fairly similar across the three groups, would identify a four or five class LCA solution. However, it is inappropriate to do a sensitivity test in the current study since changing the indicators of latent class analysis results in a totally different model (Muthén, 2002; NylundGibson \& Masyn, 2016; Samuelsen \& Raczynski, 2013). As we tested the model that we proposed given the literature we drew on from the Parental Involvement domain, we encourage future research to investigate this issue. Third, despite the robust results, we cannot explain why some parents belonged to certain classes or why some covariates were associated with their membership in these classes, as strong qualitative studies are needed in this area to understand these different groups. We also note that throughout this study, an individual parent's subgroup is not a fixed condition, as the model is a probability model only. A parent is more or less like any one of these three groups, rather than classified exclusively as one of the groups and not any of the others. Any one parent on average will exhibit indications of all three groups in some proportion, as the entropy and model fit statistics show that the model is a good fit to the data, but certainly far from a perfect fit. Fourth, we admit the homogenization of the data, and these data may not tell the full story. Fifth, throughout the analyses and discussion, we ignore within group differences within broad ethnic categories, i.e., Hispanic and Asian, and this becomes problematic when the study attempts to draw conclusions about cultural differences. Yet, we our analysis was limited by the general categories of Asian and Hispanic since the ELS:2002 dataset does not break down the two categories into specific subgroups. Sixth, the study findings are necessarily limited by the nature of the variables available in the dataset. For example, volunteering in school and the other involvement variables that distinguish the Advocate type may not fully capture the concept of Helicopter parenting as it is understood in the literature. Seventh, in an effort to facilitate interpretation of findings, we should include parent immigrant or generation status and school ethnic composition as an additional covariate. However, the public ELS:2002 data do not have those variables and we encourage future work to include these variables as covariates. Eighth, a completely different model, a Latent Profile Analysis (LPA) or a model that mixes LPA and LCA, may be of interest for future research, perhaps with a dataset that includes all of the Parental Involvement domains as Likert Scaled items. This is outside the scope of the present study. We encourage future research in this area.

\section{IMPLICATIONS AND CONCLUSIONS:}

We need a social justice oriented theory for Parental Involvement in schools to design policies to ensure that teachers and school leaders interact with parents in ways that guarantee parents and students from different backgrounds and contexts obtain equitable opportunities and attention from the school, especially for students from disadvantaged contexts (Park \& Holloway, 2017). As such, our study has several implications for research and policy interventions in Parental Involvement. As noted above, low-SES parents and single parents tend to be Guiding or Lenient parents who may not have sufficient time to 
maintain regular, frequent contacts with the school. Acknowledging this issue, schools can provide specifically designed resources to these parents, perhaps through activities such as "Coffee with the Vice Principal" (Heinrichs, 2017, p.13). Leaders should spend time designing activities and settings that provide a comfortable, non-threatening atmosphere for leaders, teachers, and parents to sit together and discuss school policies taking into account special time and location needs of parents, especially for families from historically underserved communities (Khalifa, 2012). Or, schools can support parental involvement by assigning staff, offering workshops or courses, helping with childcare or transportation, or providing a parent drop-in center or lounge (US Department of Education, 2018). It should be noted that one main aim of increasing parental involvement by schools through providing support to parents is to "increase the incidence and value of conversations around learning in pupils' homes" (Goodall, 2018, p. 224). This is done through bringing together elements of success in Goodall's model, i.e., "the reflective thinking fostered by the tools provided, the creation of the wish and barriers list, and ongoing discussion with colleagues, led to a change in perception and to changed practices" (Goodall, 2018, p. 232). To fulfill the purpose of this model, teachers should be trained, and school leaders should support, interventions around parental involvement, and parental involvement should be integrated with school culture (Goodall, 2018).

Our study also has strong implications for research of historically disadvantaged groups in terms of Parental Involvement. The reason why Lenient and Guiding parents are not active in maintaining ties or contacts with the school may be that those parents are working parents who do not have sufficient time to maintain an active relationship with the school (Elicker, Noppe, Noppe, \& Fortner-Wood, 1997). Or, perhaps the school has not taken into consideration the needs of some families for specific meeting times or facilities (Hughes, Wikeley, \& Nash, 1994; Smith, 2004), especially true for students and families from historically disadvantaged groups (Khalifa, 2012; Khalifa, Gooden, \& Davis, 2016). Our findings speak to these explanations by pointing out that Asian parents or parents with at least a bachelor degree are more likely to be Lenient parents, which we infer to mean that perhaps parents with either characteristic are more likely to work long hours than those without. Still, this hypothesis needs further study. We encourage future research in this area.

There are challenges that emerge from our data and findings which are areas for future research. First, there is a need for more nuanced survey items, as the data demonstrates for the Lenient group that there may be nested subgroups. Given the previous research, we did not have items that measured the differences between the nested groups. Second, the survey is starting to age, and we look forward to future survey administrations. Third, more complex models such as multilevel latent class models may generate results that explain more variance in the data and include a stronger set of covariates that captures the school and community context.

\section{Acknowledgements:}

This research was supported by a grant from the National Science Foundation (NSF 1546653). Any opinions, findings, and conclusions or recommendations are those of the authors and do not necessarily reflect the views of funding agencies.

\section{Suggested Citation:}

Zhou, X., Bowers, A.J. (2020) A Typology of Parental Involvement in Student Experience: A Latent Class Analysis. The High School Journal, 103(2), p.99-131. https://doi.org/10.1353/hsj.2020.0005

\section{REFERENCES:}

Agasisti, T., Bowers, A. J., \& Soncin, M. (2019). School principals' leadership types and student achievement in the Italian context: Empirical results from a three-step latent class analysis. Educational Management Administration \& Leadership, 47(6), 860-886.

Amato, P. R., \& Fowler, F. (2002). Parenting practices, child adjustment, and family diversity. Journal of marriage and family, 64(3), 703-716. DOI: 10.1111/j.1741-3737.2002.00703.x

Anderson, J. O., Lin, H. S., Treagust, D. F., Ross, S. P., \& Yore, L. D. (2007). Using large-scale assessment datasets for research in science and mathematics education: Programme for International Student Assessment (PISA). International Journal of Science and Mathematics Education, 5(4), 591-614.

Anguiano, R. P. V. (2004). Families and schools: The effect of parental involvement on high school completion. Journal of Family Issues, 25(1), 61-85.

Asparouhov, T., \& Muthén, B. (2008). Multilevel mixture models. Advances in latent variable mixture models, 27-51.

Asparouhov, T., \& Muthén, B. (2014). Auxiliary variables in mixture modeling: Three-step approaches using $\mathbf{M}$ plus. Structural Equation Modeling: A Multidisciplinary Journal, 21(3), 329-341.

Aunola, K., Nurmi, J. E., Onatsu-Arvilommi, T., \& Pulkkinen, L. (1999). The role of parents' self-esteem, mastery-orientation and social background in their parenting styles. Scandinavian Journal of Psychology, 40(4), 307-317. DOI: 10.1111/14679450.404131

Baumrind, D., \& Black, A. E. (1967). Socialization practices associated with dimensions of competence in preschool boys and girls. Child development, 291-327. DOI: 10.2307/1127295

Baumrind, D. (1971). Current patterns of parental authority. Developmental psychology, 4(1p2), 1. DOI: $10.1037 / \mathrm{h} 0030372$

Baumrind, D. (1973). The development of instrumental competence through socialization. In Minnesota symposium on child psychology (Vol. 7, pp. 3-46). 
Bauer, D. J., \& Curran, P. J. (2003). Distributional assumptions of growth mixture models: Implications for overextraction of latent trajectory classes. Psychological Methods, 83(3), 338-363. DOI: $10.1037 / 1082-989 X .8 .3 .338 \mathrm{v}$

Bowers, A. J. (2010). Analyzing the longitudinal K-12 grading histories of entire cohorts of students: Grades, data driven decision making, dropping out and hierarchical cluster analysis. Practical Assessment Research and Evaluation, 15(7), 1-18.

Bowers, A. J., Blitz, M., Modest, M., Salisbury, J., \& Halverson, R. (2017). Is There a Typology of Teacher and Leader Responders to CALL, and Do They Cluster in Different Types of Schools? A Two-Level Latent Class Analysis of CALL Survey Data. Teachers College Record (119), 4. https://www.tcrecord.org/Content.asp? contentid=21677

Bowers, A. J., Sprott, R., \& Taff, S. A. (2012). Do we know who will drop out? A review of the predictors of dropping out of high school: Precision, sensitivity, and specificity. The High School Journal, 77-100.

Bowers, A. J., \& White, B. R. (2014). Do Principal Preparation and Teacher Qualifications Influence Different Types of School Growth Trajectories in Illinois? A Growth Mixture Model Analysis. Journal of Educational Administration, 52(5), 705736. DOI: 10.1108/JEA-12-2012-0134

Boyce, J., \& Bowers, A. J. (2016). Principal Turnover: Are There Different Types of Principals Who Move From or Leave Their Schools? A Latent Class Analysis of the 2007-2008 Schools and Staffing Survey and the 2008-2009 Principal Follow-Up Survey. Leadership and Policy in Schools, 15(3), 237-272. DOI: 10.1080/15700763.2015.1047033

Brasseur-Hock, I. F., Hock, M. F., Biancarosa, G., Kieffer, M. J., \& Deshler, D. D. (2011). Adolescent struggling readers in urban schools: Results of a latent class analysis. Learning and Individual Differences, 21(4), 438-452. DOI: 10.1016/j.lindif.2011.01.008

Cheng A., Kopotic K., \& Zamarro, G. (2017). Can Parents' Growth Mindset and Role Modelling Address STEM Gender Gaps? EDRE Working Paper No. 2017-07. DOI: $10.2139 /$ ssrn.2920623

Coleman, J., Hoffer, T., \& Kilgore, S. (1982). Achievement and segregation in secondary schools: A further look at public and private school differences. Sociology of education, 55(2), 162182. DOI: $10.2307 / 2112296$

Collins, L. M., \& Lanza, S. T. (2010). Latent Class and Latent Transition Analysis: With Applications in the Social, Behavioral, and Health Sciences. Hoboken, NJ: Wiley.
Crozier, G. (2001). Excluded Parents: the deracialisation of parental involvement [1]. Race Ethnicity and Education, 4(4), 329-341. DOI: 10.1080/13613320120096643

Cusick, P. A. (1992). The educational system: Its nature and logic. McGraw-Hill College.

Domina, T. (2005). Leveling the home advantage: Assessing the effectiveness of parental involvement in elementary school. Sociology of Education, 78, 233-249. DOI: $10.1177 / 003804070507800303$

Dziak, J. J., Lanza, S. T., \& Tan, X. (2014). Effect Size, Statistical Power, and Sample Size Requirements for the Bootstrap Likelihood Ratio Test in Latent Class Analysis. Structural Equation Modeling: A Multidisciplinary Journal, 119. DOI: $10.1080 / 10705511.2014 .919819$

Education Week Research Center. (2017). Education Week Research Center Analysis of National Household Education Survey. Retrieved from http://www.edweek.org/

Elicker, J., Noppe, I., Noppe, L., \& Fortner-Wood, C. (1997). The parent-caregiver relationship scale: Rounding out the relationship system in infant child care. Early Education and Development, 8, 83-100. DOI: 10.1207/s15566935eed0801_7

Enders, C. K. (2010). Applied missing data analysis. New York: Guilford Press.

Epstein, J. L. (1995). School/family/community partnerships. Phi delta kappan, 76(9), 701.

Fan, W., \& Williams, C. M. (2010). The effects of parental involvement on students' academic self-efficacy, engagement and intrinsic motivation. Educational Psychology, 30(1), 53-74. DOI: $10.1080 / 01443410903353302$

Fan, X., Chen M. (2001). Parental involvement and students' academic achievement: A meta-analysis. Educational Psychology, 13, 1-22. DOI: 10.1023/A:1009048817385

Fehrmann, P. G., Keith, T. Z., \& Reimers, T. M. (1987). Home influence on school learning: Direct and indirect effects of parental involvement on high school grades. The Journal of Educational Research, 80(6), 330-337.

Fleischmann, F., \& de Haas, A. (2016). Explaining parents' school involvement: The role of ethnicity and gender in the Netherlands. The Journal of Educational Research, 109(5), 554565. DOI: 10.1080/00220671.2014.994196

Friedel, J. M., Cortina, K. S., Turner, J. C., \& Midgley, C. (2007). Achievement goals, efficacy beliefs and coping strategies in mathematics: The roles of perceived parent and teacher goal emphases. Contemporary Educational Psychology, 32(3), 434-458. DOI: 
Goldring, E. B., \& Phillips, K. J. (2008). Parent preferences and parent choices: The public-private decision about school choice. Journal of Education Policy, 23(3), 209-230. DOI: 10.1080/02680930801987844

Gonzales, N., Wong, J., Toomey, R., Millsap, R., Dumka, L., \& Mauricio, A. (2014). School engagement mediates long-term prevention effects for Mexican American adolescents. Prevention Science, 15(6), 929-939. DOI: 10.1007/s11121-0130454-y

Goodall, J. (2013). Parental belief and parental engagement: how do they interact?. Journal of Beliefs \& Values, 34(1), 87-99. DOI: $10.1080 / 13617672.2013 .759352$

Goodall, J. (2018). A toolkit for parental engagement: from project to process. School Leadership \& Management, 38(2), 222-238. DOI: $10.1080 / 13632434.2018 .1430689$

Goodall, J., \& Montgomery, C. (2014). Parental involvement to parental engagement: a continuum. Educational Review, 66(4), 399-410. DOI: 10.1080/00131911.2013.781576

Graves, K.E., \& Bowers, A.J. (2018). Toward a typology of technology-using teachers in the "new digital divide": A latent class analysis (LCA) of the NCES Fast Response Survey System Teachers' Use of Educational Technology in U.S. Public Schools, 2009 (FRSS 95). Teachers College Record.

Gregory, A., \& Huang, F. (2013). It Takes a Village: The Effects of 10th Grade College-Going Expectations of Students, Parents, and Teachers Four Years Later. American journal of community psychology, 52(1-2), 41-55. DOI: 10.1007/s10464-013-9575-5

Grolnick, W.S., \& Slowiaczek, M.L. (1994). Parents' involvement in children's schooling: A multidimensional conceptualization and motivational model. Child Development, 65, 237-252. DOI: 10.1111/j.1467-8624.1994.tb00747.x

Harwell, M., \& LeBeau, B. (2010). Student eligibility for a free lunch as an SES measure in education research. Educational Researcher, 39(2), 120-131. DOI: 10.3102/0013189X10362578

Heinrichs, J. (2017). School leadership based in a philosophy and pedagogy of parent engagement. School Leadership \& Management, 1-15. DOI: 10.1080/13632434.2017.1406905

Henderson, A. T., \& Mapp, K. L. (2002). A New Wave of Evidence: The Impact of School, Family, and Community Connections on Student Achievement. Annual Synthesis 2002. National Center for Family and Community Connections with Schools.

Henry, K. L., \& Muthén, B. (2010). Multilevel latent class analysis: An application of adolescent smoking typologies with individual and contextual predictors. Structural Equation Modeling, 17(2), 193-215. DOI: 10.1080/10705511003659342

Zhou \& Bowers (2020)
Hetherington, E. M. (1981). Cognitive Performance, School Behavior, and Achievement of Children from One-Parent Households.

Hill N. E., Tyson D. F. (2009) Parental involvement in middle school: A meta-analytic assessment of the strategies that promote achievement. Developmental Psychology, 45, 740-763. DOI: $10.1037 / \mathrm{a} 0015362$

Hollingshead, A. B. (1949). Elmtown's youth: The impact of social classes on adolescents. New York: John Wiley.

Hollingshead, A. B. (1975). Elmtown's youth and Elmtown revisited. New York: Wiley.

Hoover-Dempsey, K. V., Bassler, O. C., \& Brissie, J. S. (1987). Parent involvement: Contributions of teacher efficacy, school socioeconomic status, and other school characteristics. American Educational Research Journal,24(3), 417-435. DOI: 10.3102/00028312024003417

Hofferth, S. L. (2003). Race/ethnic differences in father involvement in two-parent families: Culture, context, or economy?. Journal of Family Issues, 24(2), 185-216.

Hughes, M., Wikeley, F., \& Nash, T. (1994). Parents and their Children's Schools. Blackwells.

Hunt, J. (2008). Make room for daddy... and mommy: Helicopter parents are here. The Journal of Academic Administration in Higher Education, 4(1), 9-11.

Huver, R. M., Otten, R., de Vries, H., \& Engels, R. C. (2010). Personality and parenting style in parents of adolescents. Journal of Adolescence, 33(3), 395-402. DOI: 10.1016/j.adolescence.2009.07.012

Ing, M. (2014). Can parents influence children's mathematics achievement and persistence in STEM careers?. Journal of Career Development, 41(2), 87-103. DOI: $10.1177 / 0894845313481672$

Ingels, S. J., Pratt, D. J., Alexander, C. P., Jewell, D. M., Lauff, E., Mattox, T. L., \& Wilson, D. (2014). Education Longitudinal Study of 2002 (ELS: 2002) Third Follow-up Data File Documentation. NCES 2014-364. National Center for Education Statistics.

Ingels, S. J., Pratt, D. J., Wilson, D., Burns, L. J., Currivan, D., Rogers, J. E., \& Hubbard-Bednasz, S. (2007). Education Longitudinal Study of 2002 (ELS: 2002): Base-Year to Second Follow-Up Data File Documentation. NCES 2008-347. National Center for Education Statistics.

Jackson, A. P., \& Scheines, R. (2005). Single mothers' selfefficacy, parenting in the home environment, and children's 
development in a two-wave study. Social Work Research, 29(1), 7-20. DOI: $10.1093 / \mathrm{swr} / 29.1 .7$

Jeynes, W.H. (2005). A meta-analysis of the relation of parental involvement to urban elementary school student academic achievement. Urban Education, 40, 237-269. DOI: $10.1177 / 0042085905274540$

Jeynes, W. H. (2007). The relationship between parental involvement and urban secondary school student academic achievement: A meta-analysis. Urban education, 42(1), 82-110. DOI: $10.1177 / 0042085906293818$

Jeynes, W. H. (2018). A practical model for school leaders to encourage parental involvement and parental engagement. School Leadership \& Management, 38(2), 147-163. DOI: $10.1080 / 13632434.2018 .1434767$

Johnson, J. W. (2016). "All I Do is Win... No Matter What": Low-Income, African American Single Mothers and their Collegiate Daughters' Unrelenting Academic Achievement. The Journal of Negro Education, 85(2), 156-171. DOI: 10.7709/jnegroeducation.85.2.0156

Juang, L. P., Qin, D. B., \& Park, I. J. (2013). Deconstructing the myth of the "tiger mother": An introduction to the special issue on tiger parenting, Asian-heritage families, and child/adolescent well-being. Asian American Journal of Psychology, 4(1), 1. DOI: $10.1037 / \mathrm{a} 0032136$

Jung, T., \& Wickrama, K. A. S. (2008). An introduction to latent class growth analysis and growth mixture modeling. Social and Personality Psychology Compass, 2(1), 302-317. DOI: 10.1111/j.1751-9004.2007.00054.x

Keith, T. Z., Reimers, T. M., Fehrmann, P. G., Pottebaum, S. M., \& Aubey, L. W. (1986). Parental involvement, homework, and TV time: Direct and indirect effects on high school achievement. Journal of Educational Psychology, 78(5), 373380.

http://dx.doi.org/10.1037/0022-0663.78.5.373

Kelley, T. (2008, July 26). Dear parents: Please relax, it's just camp. The New York Times. Retrieved from http://www.nytimes.com

Khalifa, M. (2012). A re-new-ed paradigm in successful urban school leadership: Principal as community leader. Educational Administration Quarterly, 48(3), 424-467. DOI: 10.1177/0013161X11432922

Khalifa, M. A., Gooden, M. A., \& Davis, J. E. (2016). Culturally responsive school leadership: A synthesis of the literature. Review of Educational Research, 86(4), 1272-1311.

Kim, S. Y., Wang, Y., Orozco-Lapray, D., Shen, Y., \& Murtuza, M. (2013). Does "tiger parenting" exist? Parenting profiles of Chinese Americans and adolescent developmental Zhou \& Bowers (2020) outcomes. Asian American Journal of Psychology, 4(1), 7. DOI: 10.1037/a0030612

Kim, Y. (2009). Minority parental involvement and school barriers: Moving the focus away from deficiencies of parents. Educational Research Review, 4(2), 80-102. DOI: 10.1016/j.edurev.2009.02.003

Kim, Y. A., An, S., Kim, H. C. L., \& Kim, J. (2018). Meaning of parental involvement among Korean immigrant parents: A mixed-methods approach. The Journal of Educational Research, 111(2), 127-138. DOI: 10.1080/00220671.2016.1220355

Leithwood, K. (2009). Co-producing learning: The family path. http://www.curriculum.org/secretariat/coproducing/

Leithwood, K., \& Jantzi, D. (2009). A review of empirical evidence about school size effects: A policy perspective. Review of Educational Research 79 (1):464-490. DOI: $10.3102 / 0034654308326158$

LeMoyne, T., \& Buchanan, T. (2011). Does "hovering" matter? Helicopter parenting and its effect on well-being. Sociological Spectrum, 31(4), 399-418. DOI: $10.1080 / 02732173.2011 .574038$

Lightfoot, D. (2004). "Some Parents Just Don’t Care" Decoding the Meanings of Parental Involvement in Urban Schools. Urban Education, 39(1), 91-107. DOI: 10.1177/0042085903259290

Lo, Y., Mendell, N. R., \& Rubin, D. B. (2001). Testing the number of components in a normal mixture. Biometrika, 88(3), 767-778. DOI: 10.1093/biomet/88.3.767

McDowall, P. S., \& Schaughency, E. (2017). Elementary school parent engagement efforts: Relations with educator perceptions and school characteristics. The Journal of Educational Research, 110(4), 348-365. DOI: 10.1080/00220671.2015.1103687

Martin, P. (2005, February 23). What kind of parent are you? The Gardian. from https://www.theguardian.com/lifeandstyle/2005/feb/23/familyan drelationships.children

Masyn, K. E. (2013). Latent class analysis and finite mixture modeling. The Oxford handbook of quantitative methods in psychology, 2, 551-611.

Medinnus, G. R. (1962). The development of a parent attitude toward education scale. The Journal of Educational Research, 56(2), 100-103. DOI: $10.1080 / 00220671.1962 .10882899$

Muthén, B. (2002). Beyond SEM: General latent variable modeling. Behaviormetrika, 21(51), 81-118. DOI: 10.2333/bhmk.29.81 
Muthén, B., \& Asparouhov, T. (2002). Latent variable analysis with categorical outcomes: Multiple-group and growth modeling in Mplus. Mplus web notes,4(5), 1-22.

Muthén, L. K., \& Muthén, B. O. (2012). Mplus statistical modeling software: Release 7.1. Los Angeles, CA: Muthén \& Muthén.

Nylund-Gibson, K., \& Masyn, K. E. (2016). Covariates and mixture modeling: Results of a simulation study exploring the impact of misspecified effects on class enumeration. Structural Equation Modeling: A Multidisciplinary Journal, 23(6), 782797. DOI: 10.1080/10705511.2016.1221313

Nylund, K. L., Asparouhov, T., \& Muthén, B. O. (2007). Deciding on the number of classes in latent class analysis and growth mixture modeling: A Monte Carlo simulation study. Structural equation modeling, 14(4), 535-569. DOI: 10.1080/10705510701575396

Okpala, C. O., Okpala, A. O., \& Smith, F. E. (2001). Parental involvement, instructional expenditures, family socioeconomic attributes, and student achievement. The Journal of Educational Research, 95(2), 110-115. DOI: 10.1080/00220670109596579

Padilla-Walker, L. M., \& Nelson, L. J. (2012). Black hawk down?: Establishing helicopter parenting as a distinct construct from other forms of parental control during emerging adulthood. Journal of adolescence, 35(5), 1177-1190.

Park, S., \& Holloway, S. D. (2017). The effects of school-based parental involvement on academic achievement at the child and elementary school level: A longitudinal study. The Journal of Educational Research, 110(1), 1-16. DOI: 10.1080/00220671.2015.1016600

Qin, D. B., \& Han, E. J. (2014). Tiger Parents or Sheep Parents?: Struggles of Parental Involvement in Working-Class Chinese Immigrant Families. Teachers College Record, 116(8), n8.

Raudenbush, S., Rowan, B., \& Kang, S. (1991). A multilevel, multivariate model for studying school climate with estimation via the EM algorithm and application to US high school data. Journal of Educational Statistics, 16(4), 295-330. DOI: 10.3102/10769986016004295

Rumberger, R. (1995). Dropping out of middle school: A multilevel analysis of students and schools. American Educational Research Journal, 32, 583-625. DOI: 10.3102/00028312032003583

Samuelsen, K. M., \& Raczynski, K. (2013). Latent class / profile analysis. In Y. Petscher, C. chatschneider, \& D.Compton (Eds.), Applied quantitative analysis in education and the social sciences (pp. 304-328). New York: Routledge.
Schiffrin, H. H., Liss, M., Miles-McLean, H., Geary, K. A., Erchull, M. J., \& Tashner, T. (2014). Helping or hovering? The effects of helicopter parenting on college students' wellbeing. Journal of Child and Family Studies, 23(3), 548-557.

Shek, D. T. (1998). Adolescents' perceptions of paternal and maternal parenting styles in a Chinese context. The Journal of Psychology, 132(5), 527-537. DOI: 10.1080/00223989809599285

Shen, F. C., Liao, K. Y. H., Abraham, W. T., \& Weng, C. Y. (2014). Parental pressure and support toward Asian Americans' self-efficacy, outcome expectations, and interests in stereotypical occupations: Living up to parental expectations and internalized stereotyping as mediators. Journal of Counseling Psychology, 61(2), 241.

Smith, D. (2004). From Key Stage 2 to Key Stage 3: Smoothing the Transfer for Pupils with Learning Difficulties. David Fulton Publishers.

Smrekar, C., \& Cohen-Vogel, L. (2001). The voices of parents: Rethinking the intersection of family and school. Peabody Journal of Education, 76(2), 75-100. DOI: 10.1207/S15327930pje7602_5

Stendler, C. B. (1951). Social class differences in parental attitude toward school at grade I level. Child development, 3746. DOI: $10.2307 / 1125960$

Strayhorn, T. L. (2009). Accessing and analyzing national databases. Handbook of data-based decision making in education, 105-122.

Tam, W. K. (1995). Asians-A monolithic voting bloc?. Political Behavior, 17(2), 223-249.

Tofighi, D., \& Enders, C. K. (2008). Identifying the correct number of classes in growth mixture models. In G. R. Hancock \& K. M. Samuelsen (Eds.), Advances in latent variable mixture models (pp. 317-341). Charlotte, NC: Information Age Publishing, Inc.

Urick, A., \& Bowers, A. J. (2014a). The impact of principal perception on student academic climate and achievement in high school: How does it measure up. Journal of School Leadership, 24(2), 386-414.

Urick, A., \& Bowers, A. J. (2014b). What Are the Different Types of Principals Across the United States? A Latent Class Analysis of Principal Perception of Leadership. Educational Administration Quarterly, 50(1), 96-134. DOI: 10.1177/0013161x13489019

U.S. Department of Education. (2018, April). Services to support parent involvement by community type, sector, and school classification. Retrieved from https://nces.ed.gov/pubs2018/2018063.pdf 
van Tuijl, C., \& van der Molen, J. H. W. (2016). Study choice and career development in STEM fields: an overview and integration of the research. International journal of technology and design education, 26(2), 159-183. DOI: 10.1007/s10798015-9308-1

Vermunt, J. K., \& Magidson, J. (2002). Latent class cluster analysis. In J. A. Hagenaars \& A. L. McCutcheon (Eds.), Applied latent class analysis (pp. 89-107): Cambridge University Press.

Vermunt, J. K., \& Magidson, J. (2013). Latent GOLD 5.0 upgrade manual. Belmont, MA: Statistical Innovations Inc.

Vermunt, J. K., \& Magidson, J. (2007). Latent class analysis with sampling weights: A maximum-likelihood approach. Sociological Methods \& Research, 36(1), 87-111. DOI: 10.1177/0049124107301965

Warner, J. (2011, January 11). No more Mrs. nice mom. The New York Times. Retrieved from http://www.nytimes.com

Weinick, R. M., Jacobs, E. A., Stone, L. C., Ortega, A. N., \& Burstin, H. (2004). Hispanic healthcare disparities: challenging the myth of a monolithic Hispanic population. Medical care, 313-320.

Wong, S. W., \& Hughes, J. N. (2006). Ethnicity and language contributions to dimensions of parent involvement. School psychology review, 35(4), 645.

Yamamoto, Y., \& Holloway, S. D. (2010). Parental expectations and children's academic performance in sociocultural context. Educational Psychology Review, 22(3), 189-214.

Zhu, Y., Steele, F., \& Moustaki, I. (2017). A General 3-Step Maximum Likelihood Approach to Estimate the Effects of Multiple Latent Categorical Variables on a Distal Outcome. Structural Equation Modeling: A Multidisciplinary Journal, 1-14. DOI: 10.1080/10705511.2017.1324310 


\section{APPENDIX:}

\section{Mplus Code for Latent Class Analysis Model}

Title:

Data:

VARIABLE :

NAMES

MISSING

IDVARIABLE

USEVARIABLES

CATEGORICAL

CLASSES

WEIGHT

AUXILIARY

AUXILIARY

ANALYSIS :

TYPE

PROCESSORS

MITERATION

STARTS

STITERATIONS

OUTPUT :

Plot:

TYPE

SERIES

SAVEDATA:

SAVE

FILE

FORMAT

ESTIMATES
Latent Class Analysis. ! Title of the program File is "LCA.dat";

STU ID F1PNLWT BYP56A BYP56F BYP69A BYP69D BYP55A BYP55C BYP57A BYP57B BYP57K BYP73 BYP54A BYP54C BYP54D BYP53D BYP53H BYP77A BYP77E BYP77N BYP770 HISPANIC AFRAMR ASIAMR BYPARED BYP01 BYP10 BYSES1 ACADEMIC BYSCTRL URBAN RURAL ENRS ENRL ENRLL BY1OFLPZ F2EVERDO F2PS0601 F2MJR2_P F3TZHIGHDEG STEMCR STEMH STEMS;

$=\operatorname{ALL}(999) ;$

$=\mathrm{STU} I \mathrm{D}$;

$=$ BYP $56 \mathrm{~A}$ BYP56F BYP69A BYP69D BYP55A BYP55C BYP57A BYP57B BYP57K BYP73 BYP54A BYP54C BYP54D BYP53D BYP53H BYP77A BYP77E BYP77N BYP770;

$=$ BYP56A BYP56F BYP69A BYP69D BYP55A BYP55C BYP57A BYP57B BYP57K BYP73 BYP54A BYP54C BYP54D BYP53D BYP53H BYP77A BYP77E BYP77N BYP770;

$=\mathrm{C}(3)$;

$=$ F1 PNLWT;

$=($ R3STEP) HISPANIC AFRAMR ASIAMR BYPARED BYP01 BYP10 BYSES1 ACADEMIC BYSCTRL URBAN RURAL ENRS ENRL ENRLL BY1OFLPZ;

$=($ DCAT) F2EVERDO F2PS0601 F2MJR2_P F3TZHIGHDEG STEMCR STEMH STEMS;

$=$ MIXTURE missing;

$=8($ STARTS $)$;

$=5000$;

$=1500250$

$=100$;

SAMPSTAT TECH11 TECH14;

$=$ PLOT3;

$=$ BYP56A BYP56F BYP69A BYP69D BYP55A BYP55C BYP57A BYP57B BYP57K BYP73 BYP54A BYP54C BYP54D BYP53D BYP53H BYP77A BYP77E BYP77N BYP770(*);

$=\mathrm{CPROB}$;

$=$ Class.DAT;

$=\mathrm{FREE}$;

= MIXESTIMATES.DAT; 